\title{
The position of Polish experts on conservative management in patients with artery diseases of lower limbs
}

\author{
Dear Readers,
}

Peripheral artery disease (PAD) is a common disease, though not very well known and often diagnosed on a very late stage, causing not only typical complications such as intermittent claudication, critical limb ischemia or amputations, but also to cardiovascular mortality. The risk of cardiovascular death can be even II times higher in patients with symptomatic PAD than in healthy patients. The risk of heart attack, stroke or cardiovascular death is even higher, reaching almost $4 \%$ within one year, nearly equal to the risk for patients with coronary artery disease (CAD). In those patients, the 5-year mortality risk is estimated at $10-15 \%$, with cardiovascular disorders being the most likely cause of death. In patients with critical limb ischemia, the risk of cardiovascular death within one year can be as high as $25 \%$ and the risk of amputation - $30 \%$.

It is estimated that the global population of patients with PAD is over 120 million. The incidence of the diseases is 3-10\%, but in patients aged 70 and more, the incidence increases to 14-29\%. In Poland, around 4,000 people are hospitalized every year for PAD of lower limbs. The number of PAD-related amputations is over 9,000 per year. Although the methods of PAD diagnosis (e.g. ABI) are often easy and non-invasive, they are scarcely used in clinical practice. Also, optimal conservative management in the form of quitting smoking, modifying the cardiovascular risk factors and supervised exercise is often overlooked.

PAD is a major issue not only for vascular surgery, but also for many other medical specializations, including angiology, general medicine, cardiology, or diabetology. As a result of long waiting times for the next visit and lack of access to patient programmes and reimbursed drugs, patients with PAD often report to the doctor when their condition is very serious. Despite the 2017 ESC guidelines on the diagnosis and treatment of peripheral artery disease, prepared together with ESVS, not all healthcare professionals have access to the latest knowledge on PAD diagnosis and treatment. Unfortunately, though published recently, the ESC's guidelines do not include some of the recent studies, among them the possibly breakthrough COMPASS trial which has the potential to change the paradigm of management of patients with PAD.

We must bear in mind that the population with PAD is a difficult patient group who need new treatment methods and optimization of the existing ones in order to visibly improve diagnosis, treatment and prognosis.

\author{
Prof. Arkadiusz Jawień, MD PhD \\ President of the Polish Society for Vascular Surgery
}

Prof. Tomasz Zubilewicz, MD PhD
Editor-in-Chief „Acta Angiologica”

Addres for Correspondence: Prof. Zbigniew Krasiński, Departament of Vascular, Endovascular Surgery, Angiology and Phlebology,

University of Medical Sciences Poznan, e-mail: zbigniew.krasinski@gmail.com 


\title{
Authors:
}

\author{
Zbigniew Krasiński', Zbigniew A. Gaciong², Filip M. Szymański, \\ Radosław Kowalewski ${ }^{4}$, Tomasz Urbanek ${ }^{5}$ \\ 'Departament of Vascular, Endovascular Surgery, Angiology and Phlebology, University of Medical Sciences Poznan, Poland \\ ${ }^{2}$ Department of Internal Medicine, Hypertension and Vascular Diseases, Medical University of Warsaw, Poland \\ ${ }^{3}$ I Department and Clinic of Cardiology, Medical University of Warsaw, Poland \\ ${ }^{4}$ Department of General, Vascular and Oncological Surgery in Multidisciplinary Hospital Warsaw-Międzylesie, Poland \\ ${ }^{5}$ Department of General and Vascular Surgery, Angiology and Phlebology, Silesian Medical University, Katowice, Poland
}

\section{Abbreviations:}

$\mathrm{ABI}$ - ankle-brachial index

ACC - American College of Cardiology

ACE - angiotensin converting enzyme

ACEI - angiotensin-converting-enzyme inhibitors

ADP - adenosine diphosphate

$\mathrm{AH}$ - arterial hypertension

AHA - American Heart Association

Angio-MR - magnetic resonance angiography

ARB - angiotensin receptor blockers

ASA - acetylsalicylic acid

CAD - coronary artery disease

CLTI - chronic limb-threatening ischemia

CV - cardiovascular system

DAPT — dual antiplatelet therapy

EBM - evidence-based medicine

ESC - European Society of Cardiology

ESVS - European Society for Vascular Surgery

FDA - Federal Drug Administration

GLP-I — glucagon-like peptide- I

GPS - good practice statement

HDL-C — high-density lipoprotein cholesterol
HIV — human immunodeficiency virus

INR - international normalized ratio

LDL-C - low-density lipoprotein cholesterol

LEAD - lower extremity artery disease

MACE - major adverse cardiac events

MWD - maximum walking distance

NNT - number needed to treat

NOAC - novel oral anticoagulants other than vitamin

$\mathrm{K}$ antagonists

OAC — oral anticoagulants

PAD - peripheral artery disease

PAR-I - proteinase-activated receptor I

PCSK9 - proprotein convertase subtilisin/kexin

type 9

PFWD - pain-free walking distance

PTD - Polish Diabetological Association

SAPT — single antiplatelet therapy

SGLT-2 — sodium/glucose cotransporter 2

$\mathrm{TBI}$ - toe-branchial index

$\mathrm{TcPO}_{2}$ - transcutaneous oxygen pressure

TIA - transient ischemic attack of the central nervous system

VKA — vitamin K antagonist 
Table of Contents:

I. Introduction

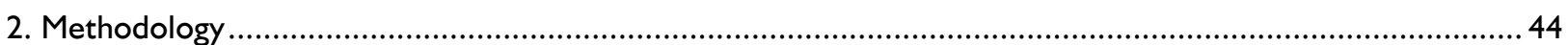

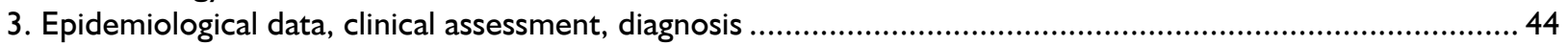

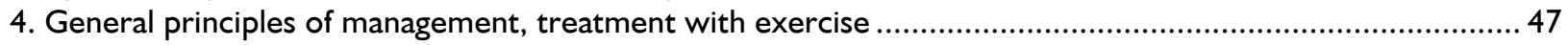

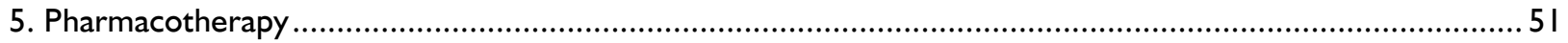

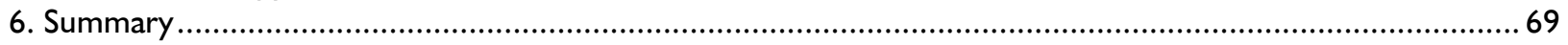

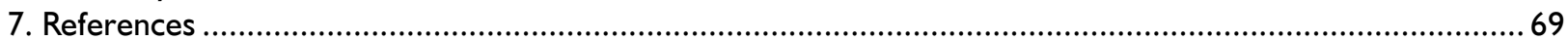

\section{Introduction}

The first decade of the $21^{\text {st }}$ century has seen major progress in the diagnosis and treatment of peripheral artery disease (PAD). The introduction of new stateof-the-art techniques of intravascular treatment, new anticoagulants and new generations of statins resulted in a large number of new scientific reports and publications allowing a more objective assessment of the outcomes of various treatment and management methods. Given the new data available and the high risk of circulatory diseases in the Polish population, it appears necessary to develop Polish guidelines on the conservative management of the lower extremity artery disease (LEAD), focusing in particular on the pharmacotherapy of patients with intermittent claudication. The guidelines should take into account the results of the latest studies and trials, and the international guidelines on the management of LEAD. The purpose of this publication is to organize the available knowledge in an accessible manner so that it could be more efficiently used by all actors involved in PAD management. The Workgroup decided to restrict the scope of this study to the lesions in lower extremities secondary to atherosclerosis and the conservative management thereof, not including the issue of PAD in other areas of the vascular system, and to the indications for revascularization treatment and the methods of revascularization in patients with LEAD.

The authors had to choose the system of classification of the strength of the guidelines and the supporting scientific evidence, especially given that the literature of the subject, including the international guidelines on the management of patients with LEAD, had been using different approaches. Following the analysis of publications on the subject at hand from the preceding 10 years, the system applied in the guidelines of the European Society of Cardiology (ESC) was adopted. The system is based on 4 classes of recommendations indicating the strength of the recommendation (I, Ila, Ilb, III), and 3 levels of evidence on which the recommendations are based (A, B, C). Both information should be provided together with a specific recommendation.
It should be pointed out that the position set out below, as well as the strength of individual recommendations, are not legally binding and thus the authors thereof cannot be legally liable for them. The following guidelines reflect the current state of the art in accordance with the principles of Evidence-Based Medicine (EBM) and are aimed at facilitating the standardization of medical care of patients with LEAD in Poland, in particular, the patients suffering from intermittent claudication. Much consideration was given to the complex issues related to anticoagulation therapy of patients with LEAD who often suffer from comorbidities which affect the indications for the use of anticoagulants (e.g. coronary artery disease or atrial fibrillation).

\section{I.I. Purpose}

The purpose of this publication on the conservative management of LEAD secondary to atherosclerosis is to organize the available knowledge and allow proper management of LEAD in line with the principles of EBM. The Workgroup's task of developing the guidelines involves not only reconciling the knowledge from the latest scientific studies, but also preparing educational tools and guideline implementation programmes, including abridged versions, summarizing slides, bulletins listing the main premises, summary cards for non-specialists, and digital versions for use in electronic appliances (such as smartphones). Digital versions of the source document will be abridged; therefore, the full text of the guidelines should be referenced.

\section{I.2. Patient groups to whom the position applies}

The developed position applies to patients with LEAD secondary to atherosclerosis.

\section{I.3. Receivers of the position}

The receivers of the position are doctors of all specializations who provide both general and specialized care for the aforementioned patients with LEAD. 


\section{I.4. Intervention types provided for in the position}

The recommendations provided in the position include the diagnostic tests used for the diagnosis and atherosclerotic assessment of LEAD, as well as pharmacotherapy and non-pharmacological methods of management thereof (excluding interventional treatment).

\section{I.5. Instructions on the use of the position}

The position set out herein should not be viewed as a legally binding standard of care for all patients, since the document contains only guidelines for management, and the recommendations should aid doctors in making optimal decisions in everyday clinical practice. The proper patient care always depends on the individual conditions of the patient, the available and feasible methods of treatment, and many more factors; decisions on the applied management must always be made by the attending physician or the medical team, in consultation with the patient or, if necessary, the patient's guardian. The authors of the guidelines encourage doctors and medical professionals to implement and popularize the following guidelines for the management of adult patients with LEAD.

\section{Methodology}

\section{I. Workgroup}

The position was developed by the Polish experts/ /specialists in angiology, hypertension management, vascular surgery, internal medicine and cardiology. The Workgroup was composed of Professor Zbigniew Krasiński, DMSc, PhD (Head of Workgroup), Professor Zbigniew Gaciong, DMSc, PhD, Professor Tomasz Urbanek, DMSc, PhD, Filip Szymanski, DMSc, PhD, and Radosław Kowalewski, DMSc, PhD

\subsection{Description of the process of developing the position and associated documents}

Formulating the propositions of guidelines, the experts took into account the 2017 ESC guidelines on the diagnosis and treatment of PAD, developed together with the European Society for Vascular Surgery [I], the 2016 guidelines of the American Heart Association (AHA) and the American College of Cardiology (ACC) on the management of patients with LEAD [2], the 2015 guidelines of the Society for Vascular Surgery on the management of asymptomatic LEAD and intermittent claudication [3], and other scientific studies and publications from recent years, especially those released after the publication of the aforementioned guidelines.

Formulating the recommendations in the Polish position, the experts analyzed the source guidelines in terms of applying them in a Polish setting. The de- veloped propositions for the recommendations were discussed in detail during meetings. Any disputes were discussed and settled. The preliminary version of the Polish position was then submitted for external consultations and reviews. Any justified comments on the substance of the guidelines were taken into consideration by the Workgroup. All experts in the Workgroup accepted the final version of the document.

\subsection{Classification of the strength}

\section{of recommendations and level of evidence}

In this document, the system of classification of recommendations and levels of evidence proposed by the ESC was adopted (Tables IA and IB). The level of evidence was assessed as high (A), moderate (B) or low (C). The strength of a recommendation was classified based on the authors' opinion that the given management procedure was justified and would bring more benefits than harm. Class I ("it is recommended") and III ("it is not recommended") are strong recommendations, while class Ila ("it is reasonable") and IIb ("may be reasonable") are conditional/weak recommendations. In the absence of existing recommendations, related e.g. to the results of the latest studies, the Workgroup attempted to formulate the so-called good practice statement (GPS), i.e. a reconciled opinion of all experts.

\section{Epidemiological data, clinical assessment, diagnosis}

\section{I. Prevalence and causes} of chronic limb ischemia

The lower extremity artery disease (LEAD) is one of the most frequent peripheral artery diseases, the prevalence of which increases with the age of the observed population. On the basis of epidemiological data, the incidence of chronic limb ischemia is estimated at $3-10 \%$, and in the population aged 70 or above, occurs $15-20 \%$, more frequently in males [4]. In its initial stage, the disease is asymptomatic. In the studies based on the ankle-brachial index $(A B I)$, which allows an objective diagnosis, the ratio of asymptomatic patients to the general number of confirmed cases ranges from $1: 3$ to $I: 5[1,4-6]$. The incidence of critical limb ischemia is $200-1,000$ new cases per I million members of the population and is significantly higher in diabetic populations $[1,4,5]$. The key factors leading to LEAD include age, smoking, hyperlipidemia, the co-occurrence of diabetes or impaired glucose tolerance, and arterial hypertension $[1,4,5]$. Other factors which play a part in the development of chronic ischemia include sex, ethnicity, vascular lesions in kidney failure, as well as the C-reactive protein level, hyperfibrinogenemia and hyperhomocysteinemia [I]. Genetic factors are also 
Table IA. Classes of recommendations

\begin{tabular}{|l|l|}
\hline I & $\begin{array}{l}\text { Evidence from scientific studies and/or general agreement that a given procedure or treatment is beneficial, } \\
\text { useful and effective } \\
\text { Is recommended... }\end{array}$ \\
\hline Ila & $\begin{array}{l}\text { Weight of evidence and/or opinion is in favour of usefulness or efficacy of the given procedure or treatment } \\
\text { Should be considered... }\end{array}$ \\
\hline IIb & $\begin{array}{l}\text { Usefulness or efficacy of the given procedure or treatment is less well established by evidence and/or opinion } \\
\text { May be considered... }\end{array}$ \\
\hline III & $\begin{array}{l}\text { Evidence from scientific studies and/or general agreement that the given procedure or treatment is not useful } \\
\text { or effective, and in some cases may be harmful } \\
\text { Is not recommended... }\end{array}$ \\
\hline
\end{tabular}

Table IB. Level (quality) of evidence
A - Data derived from multiple randomized clinical trials or meta-analyses
B - Data derived from a single randomized clinical trial or large non-randomized studies
C - Consensus of opinion of the experts and/or data derived from small studies, retrospective studies, registries

considered, although their identity and impact are still being studied $[\mathrm{I}, 5]$.

The lesions causing chronic limb ischemia are often accompanied by atherosclerotic lesions in other areas of the vascular system, which increase the cardiovascular risk, in particular, the risk of a heart attack and ischemic stroke [5]. In patients with atherosclerotic LEAD, the risk of mortality caused by coronary artery disease is increased 4-fold, and the incidence of brain ischemic episodes increases 2- to 3-fold [7-10]. In most cases, chronic lower limb ischemia is accompanied by atherosclerotic arterial lesions (95-98\% of cases), although the chronic lower limb ischemia may also be caused by other diseases or clinical conditions [I, 4]. These include inflammatory vascular diseases, history of arterial embolism, vascular stenosis or occlusion in compressive lesions or sustained injuries and the consequences thereof, thrombosed popliteal artery embolism, complications of intra-arterial injections, or the less frequent vascular tumours [I, 4]. Diabetes is a key factor in the development of atherosclerotic lesions. Diabetic lesions usually coincide with the atherosclerotic process and lead to increased vascular wall rigidity not only by thickening but also by intravascular calcifications [4, 5]. In terms of symptomatology and treatment options, the involvement of lower leg arteries, a typical condition in diabetic patients, is of particular clinical importance, as it is a risk factor of critical ischemia in patients from this group $[1,4]$.

\subsection{Symptomatology and classification of chronic limb ischemia}

Most patients do not experience clinical symptoms and the condition can be identified on the basis of decreased $A B I$ level $(<0.90)$ or the lack of pulse in leg arteries. The latest edition of ESC guidelines distinguishes a patient subgroup with "masked", i.e. a hidden form of LEAD. Those patients can suffer from severe disease but not report any symptoms due to the inability to cover a distance long enough for LEAD symptoms to manifest themselves (e.g. because of disability caused by another condition, such as heart failure), and/or reduced pain sensitivity (e.g. in patients with diabetic neuropathy) [I]. The patients in this group are usually elderly individuals, often suffering from neuropathy and other comorbidities. The subgroup with masked LEAD is exposed to high risk of limb-related incidents, which explains why some patients rapidly deteriorate from asymptomatic to sever LEAD.

One of the most typical symptoms of LEAD is intermittent claudication, which may affect different parts of the limb depending on the level of vascular occlusion/ stenosis. The most frequent location of single-level stenosis in lower extremities is the femoral artery; however, as the disease progresses, multilevel atherosclerotic lesions develop. Clinically, the presence of occlusion and/or stenosis in the aorto-iliac or femoral-popliteal segment, and peripheral lesions involving the lower leg and foot can be distinguished [5]. The lesions are often 
multilevel or located also in other areas of the vascular system. The occlusion of the femoral artery causes intermittent claudication which usually affects the lower leg muscles. The occlusion in the aorto-iliac segment can cause gluteal claudication - this condition usually accompanies the occlusion of the internal iliac artery. Stenosis or occlusion of iliac and/or pelvic vessels can also cause erectile dysfunction in men. In the case of occlusion of the lower leg vessels and impaired blood flow to the foot, the most typical symptoms, aside from lower leg pain, are observed in the foot $[5, \mathrm{II}]$.

The severity of LEAD symptoms depends on factors related to both the location and extent of atherosclerotic lesions and the degree of development of collateral circulation [ 1,4$]$. Aside from intermittent claudication, in the case of a chronic form of the disease, a number of irregularities can be observed in physical examination, such as muscular dystrophy, poor filling of superficial veins, loss of hair, weak capillary action, and paleness of the limb skin. If the ischemic symptoms deteriorate, necrotic lesions or ulceration can occur. Necrotic lesions (dry or liquefactive) initially affect the most distal parts of the extremity (toes, forefoot, calcaneal tuber area), and sites exposed to local chronic injuries (caused e.g. by compression), such as toes, heel and the Ist and 5 th metatarsal bone heads. The progression of atherosclerotic lesions and deteriorating ischemia can lead to critical limb ischemia, which deteriorates prognosis. In patients with stable intermittent claudication, the risk of amputation over a 5-year follow-up period is relatively low; with proper management, it is approx. $2-3 \%$ within 5 years, and in $5-10 \%$ of those cases, critical limb ischemia will occur [4]. The risk of deterioration of the symptoms of intermittent claudication in the further 5 years of the disease is estimated at 10-20\%, whereby the risk is highest in the first year following the diagnosis (6-9\%) and reduced in subsequent years (2-3\%/year) [12]. Differential diagnosis of intermittent claudication should take into consideration other potential causes of claudication, including claudication related to neurological diseases (e.g. nerve root or spinal cord compression), claudication of venous origin (occlusion, e.g. in the proximal segment of the venous system), chronic compartment syndrome, and other clinical conditions causing pain of the lower extremities [4]. A prerequisite for the diagnosis of critical limb ischemia is the confirmation of pain persisting for 2 weeks, or necrotic signs (stage III or IV ischemia according to Fontaine classification). Persistent pain in ischemia usually occurs with the blood pressure at the ankle below 50 $\mathrm{mm} \mathrm{Hg}$, or the pressure in big toe below $30 \mathrm{~mm} \mathrm{Hg}$. The level of partial oxygen pressure in percutaneous measurement $(\mathrm{tcPO})$ considered to be critical is below $30 \mathrm{~mm} \mathrm{Hg}$ [4]. The proposed and applied leg ischemia
Table 2A. Fontaine classification of chronic limb ischemia

\begin{tabular}{|l|l|}
\hline Stage & Clinical symptoms \\
\hline I Ila & $\begin{array}{l}\text { Mild claudication - claudication distance } \\
\text { above } 200 \mathrm{~m}\end{array}$ \\
\hline II b & $\begin{array}{l}\text { Moderate or severe claudication — claudica- } \\
\text { tion distance below } 200 \mathrm{~m}\end{array}$ \\
\hline III & Ischemic rest pain \\
\hline IV & Ulceration or gangrene \\
\hline
\end{tabular}

Table 2B. Rutherford classification of chronic limb ischemia

\begin{tabular}{|l|l|}
\hline Category & Clinical symptoms \\
\hline 0 & Asymptomatic \\
\hline 1 & Mild claudication \\
\hline 2 & Moderate claudication \\
\hline 3 & Severe claudication \\
\hline 4 & Ischemic rest pain \\
\hline 5 & Minor tissue loss \\
\hline 6 & Major tissue loss \\
\hline
\end{tabular}

classifications according to Fontaine and Rutherford are outlined in Tables 2A and 2B.

\subsection{Diagnosis of chronic limb ischemia \\ - clinical assessment and additional tests}

The basic method for diagnosing chronic limb ischemia is a physical examination. Due to the possible lack of pulse in the limbs of some patients unrelated to LEAD, as well as the subjective nature of the ailments, the diagnostic algorithm must include additional tests $[1,4,5]$.

Aside from assessing the pain and intermittent claudication, an important element of the physical examination is collecting the history of other atherosclerotic circulatory diseases, such as the coronary artery disease, stroke, transient ischemic attack, chronic mesenteric ischemia and other conditions of the circulatory system, such as arterial hypertension, arrhythmias (including atrial fibrillation) and heart failure. Equally important is the assessment of comorbidities, obesity and the patient's habits (physical activity, smoking, a diet with high fat or carbohydrate content) [I]. It is necessary to assess the cardiovascular risk factors identified mainly on the basis of laboratory tests, such as lipid disorders, diabetes or kidney failure, which affect the progression of ischemic lesions [I]. Aside from the assessment of 
the site condition, the physical examination must also include measuring the pulse in typical sites on lower extremities (femoral artery, popliteal artery, dorsal artery of the foot, and posterior tibial artery).

In order to acquire an objective assessment of the stage of ischemia, the clinical assessment should be supplemented with additional tests. One of the most basic test methods is the measurement of $A B I[I, 4]$. Decreased $A B I$ level correlates with the increase of cardiovascular risk [ $1,4,13-16]$. It is generally accepted that $A B I$ level $\leq 0.9$ signals chronic limb ischemia (limit values 0.9-I.0; normal range: I-I.4). In the event of measuring different pulse values in the dorsal artery of the foot and the posterior tibial artery of the same limb, the higher of the two values is used in the diagnosis of LEAD [4]. In patients with diseases causing increased arterial wall rigidity, e.g. diabetes, $A B I$ level may increase to above 1.4; in such cases, the parameter cannot be used in the assessment of the severity of ischemia [ 1,4 , 5]. In patients with diabetes and the potential increase of lower leg arterial wall rigidity, the parameter allowing a more reliable assessment of the blood flow in the limb is the toe-brachial index (TBI). The measurement is taken by placing the sleeve on the big toe; the pressure value is read by the continuous-wave Doppler ultrasound transducer or a plethysmograph. TBI values below 0.7 are considered abnormal [ 17]. In patients with intermittent claudication, in order to objectively assess the distance covered without pain, a treadmill walking test can be performed. It is recommended to perform the standardized test, with the treadmill inclination of 12 degrees and speed of $3.2 \mathrm{~km} / \mathrm{h}[\mathrm{I}, 4,5]$. The $\mathrm{tcPO}_{2}$ measurement may be useful both in the identification of chronic limb ischemia and the assessment of healing of wounds of ischemic origin. Other methods of assessing the microcirculation vessels, including laser Doppler flowmetry and capillaroscopy, are used much less frequently and mainly for scientific purposes.

The next group of additional tests performed in patients with LEAD are imaging test. In most cases, a duplex Doppler ultrasound examination is indicated, as it allows locating and assessing the stage of stenosis/ /occlusion. If the patient requires surgical treatment, a more objective and more comprehensive assessment of limb arteries is needed, including the aorta and iliac arteries. The first-line test is computed tomography (CT) angiography; however, as the method employs a contrast agent, it may deteriorate renal function, especially in patients who are already suffering from renal impairment. An alternative method is magnetic resonance angiography (MRA), but the availability of this test is still limited, the image recording time is much longer, and there is also the risk of contrast agent-induced complications [I, 4]. MRA can be performed without the contrast agent but at the cost of worse visibility of the lesions and a higher number of artefacts. Diagnosis of small vessels is challenging, especially an objective assessment of the vessels of the lower leg and the foot, particularly when vessel wall calcifications are present, e.g. in diabetic patients. The reference method providing the most accurate and precise image of the lower leg and the foot (in particular in patients with diabetic peripheral lesions) is still conventional angiography $[1,4]$.

Angiography using puncture technique is currently considered justified mainly when a simultaneous therapeutic procedure (revascularization) is planned. An exception is the aforementioned diagnosis of the vessels of the lower leg and the foot in diabetic patients with peripheral lesions since invasive angiography is able to image this vascular segment much more efficiently than other methods.

The recommendations for the medical interview, the physical examination and diagnostic tests in patients with atherosclerotic LEAD are outlined in Table 3.

\section{General principles of management, treatment with exercise}

The management of patients with LEAD involves two main elements: treatment in order to reduce the global cardiovascular risk, and treatment aimed at the symptoms and risk related to the occurrence of lesions in the arteries of lower extremities, in order to reduce the symptoms in the extremity and/or save the extremity from amputation. The management recommended for reducing the global cardiovascular risk, involving non-pharmacological methods and pharmacotherapy, is similar for all patients with PAD, regardless of the area of the vascular system in which the symptoms of atherosclerotic lesions occur. The treatment targeting local lesions in the arteries of lower extremities is typical for LEAD management.

Non-pharmacological methods - according to the 2017 ESC guidelines [I] on the management of patients with PAD, the following is recommended for all patients in this group:

I) quitting smoking (class of recommendation lb);

2) healthy diet and physical exercise (class of recommendation Ic).

The notion-pharmacological prevention strategies can also be beneficial in terms of reducing limb incidents. In terms of both the improvement of the symptoms and the reduction of the cardiovascular risk, the most beneficial strategy is the combination of the recommended methods, i.e. quitting smoking alone will have little effect on the walking distance, but combined with exercise training, it will improve 
Table 3. Medical interview, physical examination and diagnostic tests for patients with atherosclerotic lower extremity artery disease

\begin{tabular}{|c|c|c|}
\hline Recommendations and instructions & $\begin{array}{l}\text { Class of } \\
\text { recommendation }\end{array}$ & $\begin{array}{l}\text { Level (quality) } \\
\text { of evidence }\end{array}$ \\
\hline \multicolumn{3}{|l|}{ Medical interview and physical examination } \\
\hline $\begin{array}{l}\text { In the case of patients with increased risk of LEAD (see Table 4), medical interviews } \\
\text { should be collected on the symptoms in lower extremities, among them intermittent } \\
\text { claudication and unusual exercise symptoms, deterioration of walking efficiency, ischemic } \\
\text { rest pain and non-healing wounds of lower extremities. Also, the presence of other } \\
\text { circulatory diseases secondary to atherosclerosis and their risk factors should be assessed }\end{array}$ & I & C \\
\hline $\begin{array}{l}\text { In patients from the increased LEAD risk group (see Table } 4 \text { ) and/or with the symptoms } \\
\text { suggesting LEAD, the vascular system of the lower extremities should be examined, in- } \\
\text { cluding the assessment of pulse in the arteries of the lower extremities, murmurs above } \\
\text { the femoral arteries, and visual examination of the lower extremities }\end{array}$ & 1 & C \\
\hline \multicolumn{3}{|l|}{ Diagnostic tests } \\
\hline $\begin{array}{l}A B I \text { measurement is recommended for patients with clinically suspected LEAD on the } \\
\text { basis of the medical interview or the physical examination }\end{array}$ & I & C \\
\hline $\begin{array}{l}\mathrm{ABI} \text { measurement may be considered for patients in the increased LEAD risk group } \\
\text { (see Table 4) without the clinical suspicion of LEAD on the basis of the medical } \\
\text { interviews or the physical examination }\end{array}$ & Ilb & C \\
\hline $\mathrm{ABI}$ measurement is recommended as the first-line method for diagnosing LEAD & 1 & C \\
\hline $\begin{array}{l}\text { In the event of clinical suspicion of LEAD in patients with } A B I>I .4 \text {, or in the event } \\
\text { of confirmed diabetes, the measurement of the toe-brachial index is recommended }\end{array}$ & I & C \\
\hline $\begin{array}{l}\text { In the patients with symptomatic LEAD who are considered for revascularization, } \\
\text { anatomical imaging methods are recommended, such as duplex ultrasound (first-line } \\
\text { method), computed tomography angiography or magnetic resonance angiography }\end{array}$ & 1 & C \\
\hline
\end{tabular}

$\mathrm{ABI}$ : ankle-brachial index; LEAD: lower extremity artery disease

Table 4. Patients with increased risk of atherosclerotic lower extremity artery disease (based on [I, 2])

Other atherosclerotic circulatory disease (coronary artery disease, peripheral artery disease in another area of the vascular system)

Heart failure

Abdominal aortic aneurysm

Chronic kidney disease

Age $\geq 65$

Patients are aged $<65$ with atherosclerosis risk factors (smoking, hyperlipidemia, arterial hypertension, diabetes), especially those in high and very high cardiovascular risk according to ESC guidelines on the prevention of circulatory diseases [18]

Patients aged $>50$ with a family history of LEAD

ESC: European Society of Cardiology; LEAD: lower extremity artery disease

the walking distance considerably. On the other hand, smoking deteriorates LEAD in patients with intermittent claudication and increases the risk of amputation $[18,19]$.
Pharmacotherapy - each patient with PAD should receive pharmacotherapy as recommended in the guidelines in order to reduce the incidence of cardiovascular events and events related to ex- 
Table 5. Recommendations on reducing the cardiovascular risk in patients with atherosclerotic lower extremity artery disease

\begin{tabular}{|c|c|c|}
\hline Recommendation & $\begin{array}{c}\text { Class of } \\
\text { recommendation }\end{array}$ & $\begin{array}{c}\text { Level (quality) } \\
\text { of evidence }\end{array}$ \\
\hline \multicolumn{3}{|l|}{ Non-pharmacological methods } \\
\hline Quitting smoking is recommended for all patients with LEAD & 1 & B \\
\hline A healthy diet and physical exercise are recommended for all patients with LEAD & 1 & C \\
\hline \multicolumn{3}{|l|}{ Lipid disorders treatment } \\
\hline Treatment with statins is recommended for all patients with LEAD & 1 & A \\
\hline $\begin{array}{l}\text { For patients with LEAD, it is recommended to reduce the LDL-C level to }<1.8 \mathrm{mmol} / \mathrm{L} \\
(70 \mathrm{mg} / \mathrm{dL}) \text {, or } \geq 50 \% \text {, if the initial } L D L-C \text { level is } 1.8-3.5 \mathrm{mmol} / \mathrm{L}(70-135 \mathrm{mg} / \mathrm{dL})\end{array}$ & 1 & $\mathrm{C}$ \\
\hline \multicolumn{3}{|l|}{ Anticoagulation treatment } \\
\hline $\begin{array}{l}\text { Long-term anticoagulation treatment is recommended for all patients with symptomatic } \\
\text { LEAD or after revascularization due to LEAD (see Table 8) }\end{array}$ & 1 & $A^{a}$ \\
\hline \multicolumn{3}{|l|}{ Arterial hypertension treatment } \\
\hline Non-pharmacological methods should be applied according to the general standards & 1 & A \\
\hline $\begin{array}{l}\text { For patients with LEAD and arterial hypertension, the recommended target blood } \\
\text { pressure is }<140 / 90 \mathrm{~mm} \mathrm{Hg}^{\mathrm{b}}\end{array}$ & 1 & A \\
\hline $\begin{array}{l}\text { All main classes of hypotensive drugs can be used, depending on the co-occurring } \\
\text { clinical conditions }\end{array}$ & lla & C \\
\hline $\begin{array}{l}\text { The inhibitors of the renin-angiotensin system (ACEI or ARB) should be considered } \\
\text { as the first-line drugs for patients with LEAD and arterial hypertension }\end{array}$ & Ila & B \\
\hline $\begin{array}{l}\text { Beta-adrenolytics should be considered for patients with LEAD and indications for } \\
\text { beta-adrenolytic therapy due to comorbidities (e.g. history of heart attack, heart failure } \\
\text { with impaired left ventricular contractile function) }\end{array}$ & Ila & B \\
\hline ACEI should not be combined with ARB in treating arterial hypertension & III & A \\
\hline \multicolumn{3}{|l|}{ Diabetes treatment } \\
\hline $\begin{array}{l}\text { Strict glycemic control and standard treatment of diabetes are recommended } \\
\text { for diabetic patients with LEAD }\end{array}$ & 1 & C \\
\hline
\end{tabular}

ACEl: angiotensin-converting-enzyme inhibitor; ARB: angiotensin receptor blocker; LDL-C: cholesterol in low-density lipoprotein fraction; LEAD: lower extremity artery disease

${ }^{a}$ Patients with symptomatic LEAD — the level of evidence A; patients after revascularization — the level of evidence $C$

${ }^{b}$ With the exception of patients, for whom higher target values might be indicated, e.g. elderly patients with frailty syndrome

tremities. The pharmacotherapy recommended for patients with PAD includes first of all anticoagulation drugs (mainly antiplatelet agents) and statins, and treatment related to any additional risk factors, such as co-occurring diabetes or arterial hypertension (see chapter 5 ).

The ESC guidelines emphasize that even if patients with LEAD are asymptomatic, the cardiovascular risk remains high and most strategies of cardiovascular events prevention are beneficial to them, in particular, strict control of the risk factors. An exception is an antiplatelet treatment which is recommended mainly for patients with symptomatic LEAD; no benefits to asymptomatic patients of administering antiplatelet agents have been confirmed.
The recommendations on the reduction of cardiovascular risk in patients with atherosclerotic LEAD are outlined in Table 5.

Symptomatic treatment - in patients with intermittent claudication, the treatment aimed at improving LEAD symptoms is based mainly on exercise training (see below). If the patient's daily activities are significantly disturbed, revascularization should be considered, combined with exercise therapy; this also applies to the situations when activity is significantly reduced despite the exercise therapy and other treatment methods. The details of the revascularization treatment of the arteries of lower extremities exceed the scope of this study. The drugs improving LEAD symptoms (mainly intermittent clau- 
Table 6. Recommendations on symptomatic treatment of patients with intermittent claudication

\begin{tabular}{|c|c|c|}
\hline Recommendation & $\begin{array}{l}\text { Class of } \\
\text { recommendation }\end{array}$ & $\begin{array}{l}\text { Level (quality) } \\
\text { of evidence }\end{array}$ \\
\hline \multicolumn{3}{|l|}{ Statins } \\
\hline $\begin{array}{l}\text { Regardless of the benefits in terms of reducing cardiovascular risk, statins are also } \\
\text { recommended to improve the walking distance }\end{array}$ & 1 & B \\
\hline \multicolumn{3}{|l|}{ Exercise therapy } \\
\hline $\begin{array}{l}\text { Supervised walking training is recommended for all patients with chronic lower limb } \\
\text { ischemia who are able to exercise. The patient should attend walking training sessions } \\
\text { for at least } 3 \text { months, and the exercise on the treadmill should be intense enough } \\
\text { to induce intermittent claudication; after each episode of claudication, the patient } \\
\text { should rest }\end{array}$ & 1 & $A$ \\
\hline $\begin{array}{l}\text { If supervised exercise training is not possible or available, unsupervised exercise } \\
\text { training/physical exercise is recommended }\end{array}$ & 1 & C \\
\hline \multicolumn{3}{|l|}{ Treatment extending the walking distance } \\
\hline $\begin{array}{l}\text { For patients with intermittent claudication, for whom elimination of risk factors and } \\
\text { walking training is not bringing sufficient improvement, symptomatic pharmacotherapy } \\
\text { may be considered to extend the patient's walking distance (See Table II) }\end{array}$ & Ilb & A \\
\hline \multicolumn{3}{|l|}{ Revascularization } \\
\hline $\begin{array}{l}\text { If despite the exercise therapy and other methods, the patient's normal functioning } \\
\text { remains disturbed, revascularization should be considered }\end{array}$ & Ila & C \\
\hline $\begin{array}{l}\text { If the patient's normal functioning remains severely disturbed, revascularization } \\
\text { combined with exercise therapy and other methods should be considered }\end{array}$ & Ila & B \\
\hline
\end{tabular}

dication) play a supporting role and are discussed in detail in item 5.3.

The recommendations on the symptomatic treatment of patients with intermittent claudication are outlined in Table 6.

\section{I. Exercise therapy}

Aside from reducing cardiovascular risk, systematic physical exercise, in particular, walking, is essential in the treatment of the symptomatic LEAD. Walking training, preferably supervised, not only extends the walking distance by improving the efficiency of the local collateral circulation but is also beneficial to the circulatory system by improving the endothelial function, reducing inflammation, increasing the pain threshold, stimulating angiogenesis, improving cell metabolism and reducing blood viscosity. Exercise therapy improves the performance of the circulatory system and the overall quality of life [I, 20-23].

The ESC guidelines [I] recommend exercise therapy for patients with intermittent claudication, preferably in the form of properly supervised walking training (class of recommendation la), and if supervised training is unavailable, unsupervised training is recommended (class of recommendation Ic). In the case of supervised exercise therapy, exercise 3 times a week is usually recommended, starting with a 30-minute training and gradually extending its length to 60 minutes. As soon as the moderate (sub-maximal) pain severity is reached during training on the treadmill, the patient should rest until the pain disappears. The next exercise cycle should follow the same principles, and the total length of the training session should be gradually extended. As the claudication distance is gradually extended with exercise, the treadmill pace and incline may be increased (the recommended initial settings are based on the assumption that pain will appear after 3-5 minutes of walking) [4]. According to a review of data from the Cochrane database on 30 randomized trials, the walking training extended the maximum walking distance (MWD) and pain-free walking distance (PFWD) [24]. Exercise therapy also improved the overall quality of life. The ESC guidelines state that supervised exercise therapy is safe and that routine screening for heart diseases is not required prior to the therapy [25], however, the patient should undergo a clinical assessment of the cardiopulmonary reserve and comorbidities in terms of his/her tolerance of the planned exercise therapy. The minimum duration of exercise therapy is 3 months $[24,26]$. The walking training also improves the long-term 
treatment outcomes in patients undergoing revascularization [27].

Supervised exercise therapy is more efficient than unsupervised one [1, 26, 28, 29], but if appropriate supervision cannot be provided to the patient, then exercise therapy at home is a useful alternative, usually in the form of intensified walking, as this type of training also improves the overall quality of life and the walking performance $[28,30]$. If the patient is unable to walk, alternative types of exercise can be used (e.g. bicycle riding, strength training or rowing machine for upper limbs - e.g. for patients after amputations), since those exercised have also been proven to be effective [29].

\section{Pharmacotherapy}

The objectives of pharmacotherapy in patients with LEAD include:

I. Reducing the risk of cardiovascular mortality and morbidity.

2. Reducing the risk of lower limb-related incidents.

3. Reducing the LEAD symptoms (mainly intermittent claudication).

4. Improving the treatment outcomes after revascularization (percutaneous or surgical).

In this patient group, pharmacotherapy involves two main elements: treatment to reduce cardiovascular risk and symptomatic treatment. Next, to the non-pharmacological methods, pharmacotherapy is the basic method of reducing the global cardiovascular risk in patients with LEAD, with a major impact on the overall prognosis. In order to reduce the risk of cardiovascular mortality and morbidity, mainly stating (see item 5.I.I) and antiplatelet drugs (see item 5.2) are used, and treatment for other risk factors, such as co-occurring diabetes (see 5.1.2) or arterial hypertension (see 5.1.3). Anticoagulation drugs are used mainly in patients with conventional indications for chronic oral anticoagulation, such as atrial fibrillation or venous thromboembolism. The data from the recently completed clinical trials indicate a potential role of direct oral anticoagulants (DOACs) in the management of LEAD (see 5.2). Some of the aforementioned drugs, in particular, the anticoagulants and statins, also reduce the risk of lower limb-related incidents and improve the outcomes of percutaneous or surgical revascularization.

Pharmacotherapy improving the LEAD symptoms (intermittent claudication) and/or improving the lower extremity function (see 5.3) is only supplementary to other methods of symptomatic treatment, such as walking training therapy and revascularization. Among the many tested pharmacological agents, the most significant improvement of the walking distance in patients with LEAD were achieved with cilostazol and naftidrofuryl; the usefulness of other drugs is less well-confirmed or unconfirmed, and they are usually not recommended by international guidelines. Some drugs used mainly to reduce the global cardiovascular risk can also play a role in symptomatic treatment, in particular, statins.

\section{I. Cardiovascular risk factors control}

\section{I.I. Hypolipidemic therapy in patients} with lower extremity artery disease

Hypolipidemic therapy, mainly with the use of statins, which are pleiotropic drugs, reduces cardiovascular morbidity and mortality, and the overall mortality in patients with overt circulatory diseases, including patients with PAD. According to ESC guidelines, it is recommended for all patients with PAD to reduce the serum level of low-density lipoprotein cholesterol (LDL-C) to $<1.8 \mathrm{mmol} / \mathrm{L}(<70 \mathrm{mg} / \mathrm{dL})$, or by $\geq 50 \%$, if the initial LDL-C level is $1.8-3.5 \mathrm{mmol} / \mathrm{L}(70-135 \mathrm{mg} / \mathrm{dL})$ [I]. This corresponds to the objectives of treatment in patients from the very high cardiovascular risk group [3]. The recent recommendations of the Cardiovascular Pharmacotherapy Section (CPS) of the Polish Cardiac Society, published in the so-called $3^{\text {rd }}$ Declaration of Sopot, specify that all patients with PAD (general atherosclerosis) and additional risk factors should be qualified into the highest risk group, called the extreme risk group in the CPS nomenclature, so their target serum LDL levels should be LDL $<35 \mathrm{mg} / \mathrm{dL}(<0.9$ $\mathrm{mmol} / \mathrm{L})$ (Table 7).

According to the current guidelines of the European Society of Cardiology and other scientific bodies, each patient with LEAD must receive statins from the attending physician (class IA recommendation) [I-3]. The results of the studies conducted thus far have shown that using statins reduces overall mortality and the incidence of cardiovascular events in patients with various stages of LEAD [3 I, 35]. Statins also significantly improve the walking distance until pain occurs and the maximum walking distance, and may reduce the incidence of adverse events in the limbs of patients with LEAD [34] (see 5.3).

In those patients who do not achieve the therapeutic goals with statins alone, statin therapy combined with ezetimibe can be beneficial [36]. A randomized clinical trial did not show a reduction of the cardiovascular risk in LEAD patients treated with bezafibrate as compared to placebo [37].

Recently, results of trials were published showing that the new, strong hypolipidemic drugs, proprotein convertase subtilisin/kexin type 9 (PCSK9), further considerably reduced the LDL-C levels and improved the clinical outcomes in patients with PAD. In the FOURIER 
Table 7. Target low-density lipoprotein levels in relation to the cardiovascular risk profile (authors'original contribution).

\begin{tabular}{|c|c|c|}
\hline Risk category & Presence of disease, risk factors or 10-year Pol-SCORE risk & Target LDL-C level \\
\hline $\begin{array}{l}\text { Extremely } \\
\text { high }\end{array}$ & $\begin{array}{l}\text { Stenting for left main coronary artery disease and/or multivessel coronary artery } \\
\text { disease (complex percutaneous coronary intervention due to multivessel coronary } \\
\text { artery disease) } \\
\text { Generalized atherosclerosis - involving multiple vascular beds with } \\
\text { additional risk factors } \\
\text { Progression of atherosclerotic cardiovascular disease despite achieving } \\
\text { and maintaining LDL-C level }<55 \mathrm{mg} / \mathrm{dL}(<\mathrm{I} .4 \mathrm{mmol} / \mathrm{L})\end{array}$ & $\begin{array}{l}<35 \mathrm{mg} / \mathrm{d} \\
(<0.9 \mathrm{mmol} / \mathrm{l})\end{array}$ \\
\hline Very high & $\begin{array}{l}\text { Progression of atherosclerotic cardiovascular disease despite achieving } \\
\text { and maintaining } \mathrm{LDL}-\mathrm{C} \text { level }<70 \mathrm{mg} / \mathrm{dL}(<\mathrm{I} .8 \mathrm{mmol} / \mathrm{L}) \\
\text { Acute coronary syndrome, established coronary, carotid, or peripheral arterial } \\
\text { disease } \\
\text { Previous revascularization } \\
\text { Pol-SCORE risk }>20 \% \\
\text { Diabetes or stage } 3-4 \text { chronic kidney disease with one or more risk factors } \\
\text { Familial hypercholesterolemia } \\
\text { History of premature atherosclerotic cardiovascular disease ( }<55 \text { years in men, } \\
<65 \text { years in women) } \\
\text { Established cardiovascular disease in patients with diabetes or stage } 3-4 \text { chronic } \\
\text { kidney disease }\end{array}$ & $\begin{array}{l}<55 \mathrm{mg} / \mathrm{dl} \\
(<1.4 \mathrm{mmol} / \mathrm{l})\end{array}$ \\
\hline High & $\begin{array}{l}\geq 2 \text { risk factors and Pol-SCORE risk } 10-20 \% \\
\text { Diabetes or stage } 3-4 \text { chronic kidney disease without other risk factors }\end{array}$ & $\begin{array}{l}<70 \mathrm{mg} / \mathrm{dl} \\
(<1.8 \mathrm{mmol} / \mathrm{l})\end{array}$ \\
\hline Moderate & $<2$ risk factors and Pol-SCORE risk $<10 \%$ & $\begin{array}{l}<100 \mathrm{mg} / \mathrm{dl} \\
(<2.6 \mathrm{mmol} / \mathrm{l})\end{array}$ \\
\hline Low & No additional risk factors & $\begin{array}{l}<I 15 \mathrm{mg} / \mathrm{dl} \\
(<3.0 \mathrm{mmol} / \mathrm{l})\end{array}$ \\
\hline
\end{tabular}

LDL-C: low-density lipoprotein cholesterol; SCORE: Systematic COronary Risk Evaluation

trial, the PCSK9 inhibitor evolocumab combined with a statin reduced the incidence of cardiovascular events in patients with the atherosclerotic circulatory disease, as compared to the treatment with statins alone [38]. Similar results were achieved in the subgroup of patients with LEAD, for whom evolocumab reduced the cardiovascular mortality and the risk of heart attack, stroke, hospitalization due to angina, or the need for coronary revascularization [39]. Furthermore, treatment with evolocumab reduced the risk of adverse limb-related events (including amputations) by $42 \%$ compared to statins alone.

The recommendations on hypolipidemic therapy in patients with LEAD are outlined in Table 5.

\section{I.2. Glycemic control in patients with lower extremity artery disease and diabetes}

For patients with PAD and co-occurring diabetes, strict glycemic control is recommended according to the general standards [ 1,40$]$. It is also believed that glycemic control is particularly important for improving the lower extremities treatment outcomes, including reducing the frequency of amputations in patients with critical limb ischemia and improving the patency after revascularization in the lower leg [4I, 42].

According to the guidelines of the Polish Diabetological Association, the first-line drug for patients with type 2 diabetes is metformin (unless there are contraindications for use) [40]. Choosing the anti-diabetic medications, it should be taken into account that the benefit of reducing the cardiovascular risk has been confirmed for only a handful of those agents. The results of large randomized clinical trials published in recent years show a reduction of the overall and cardiovascular mortality by some GLP-I receptor agonists (liraglutide among those available in Poland), and SGLT-2 inhibitors (empagliflozin) [40]. It appears that the most beneficial effects were achieved with empagliflozin which significantly reduced the overall mortality, cardiovascular mortality and morbidity (overall mortality caused by cardiovascular disorders, heart attack and stroke), and the risk of hospitalization due to heart failure [43]. In the 
recently published review of the results of EMPA-REG OUTCOME trial it was shown that in patients with type 2 diabetes and co-occurring PAD, empagliflozin reduced the cardiovascular mortality by $43 \%$ and overall mortality by $38 \%$ [44].

The recommendations on the treatment of diabetes in patients with LEAD are outlined in Table 5.

\section{I.3. Hypotensive therapy in patients with lower extremity artery disease}

\section{Arterial hypertension as a risk factor} of the peripheral artery disease

Arterial hypertension is one of the key risk factors of atherosclerosis and its complications. The analysis of causes of death provided in the World Health Organization's report shows that $\mathrm{AH}$ is responsible for one-seventh of the overall mortality [45]. Similar conclusions have been formulated from the prospective epidemiological observations of over 8 million patients from around the world, conducted under the Global Burden of Disease study [46].

Globally, arterial hypertension affects around $30 \%$ of the adult population. In Poland, data from subsequent editions of NATPOL study show that the current number of patients exceeds 10 million; if the growth tendency is maintained, the population might increase by $50 \%$ over the next decade [47].

In the population of patients with abnormal $A B I$, the percentage of patients with $\mathrm{AH}$ is $60 \%$ (Rotterdam Study) [48]; similarly, in patients with arterial hypertension, lower $A B I$ values are observed [49]. The risk of LEAD symptoms, such as intermittent claudication, is doubled in patients with $\mathrm{AH}$ than in normotensive patients [50] and usually affects untreated patients, or patients with insufficient arterial hypertension control [5I]. Among all complications of atherosclerosis, PAD appears to be most closely related to the pulse pressure; each increase of systolic pressure by $20 \mathrm{~mm} \mathrm{Hg}$ increases the risk of PAD by 63\%. [52].

Next to smoking, arterial hypertension is the main PAD progression factor; however, there is insufficient data to confirm that arterial blood pressure control would affect the progression of lesions in the peripheral arteries [53].

\section{Pharmacotherapy of arterial hypertension in patients with lower extremity artery disease}

Reducing the arterial blood pressure reduces the risk of cardiovascular complications in patients with PAD. In the clinical trials on the efficacy of hypotensive therapy, the patients with PAD were a small group, but the available data indicate that they benefit from the therapy similarly to other groups [54]. Hence, the current guidelines recommend similar management of patients with PAD as other groups of patients with arterial hypertension [1, 55]. In the ESC guidelines, the recommended target arterial blood pressure for patients with PAD and $\mathrm{AH}$ is $<140 / 90 \mathrm{~mm} \mathrm{Hg}$ (class of recommendation la) [ $\mathrm{I}$ ]. On the basis of the results of INVEST trial, in which $12 \%$ of the population was diagnosed with PAD, it is not recommended to reduce the systolic blood pressure below I 10-120 $\mathrm{mm} \mathrm{Hg}$ due to the potential increase of the cardiovascular risk [56]. In elderly patients with frailty syndrome, it is recommended to reduce the arterial blood pressure in a careful and gradual manner, controlling the patients for orthostatic hypotension, and the aforementioned target arterial blood pressure levels should be achieved only if they are well tolerated by the patients and do not cause excessive pressure drop in standing position $[57,58]$.

An important element of the management of this patient group is the change of lifestyle (quitting smoking, physical exercise, body weight reduction, reduction of salt intake to $<5-6 \mathrm{~g} /$ day). All classes of hypotensive drugs are used in treating arterial hypertension in patients with PAD. As first-line drugs in monotherapy or combined therapy, diuretics, beta-adrenolytics, calcium antagonists, angiotensin-converting-enzyme inhibitors (ACEI) and angiotensin receptor blockers (ARB) can be used. The choice of the hypotensive drug may depend on comorbidities and co-occurring clinical conditions. The European and American guidelines $[1,2]$ state that for patients with PAD, ACEl or ARB should be considered as first-line drugs (class of recommendation Ila). The preference for renin-angiotensin system inhibitors arises from the data acquired in HOPE and ONTARGET trials which showed that ramipril or telmisartan reduced the cardiovascular risk in patients with PAD [59, 60]. Those drugs were also beneficial to patients with advanced ischemia (chronic limb-threatening ischemia, CLTI). In this patient group, treatment with ACEI or ARB reduced the incidence of major cardiovascular events and mortality, without affecting the outcomes of limb ischemia treatment [6I].

Patients with PAD often have absolute indications for treatment with beta-adrenolytics, such as a history of heart attack or heart failure with impaired left ventricular contractile function. In the observational study, treatment of patients after myocardial infarction with beta-adrenolytics significantly reduced the risk of coronary events by 53\% [62]. Using drugs from this class did not affect the claudication distance in patients with mild or moderate LEAD [63]. However, caution is recommended when using those drugs in patients with critical ischemia, despite the fact that in the observational studies, even in patients with CLTI the clinical outcomes of treatment were non-inferior among the patients treated with beta-adrenolytics to patients not receiving those drugs $[64,65]$. 
Data on the beneficial effect of hypotensive drugs on intermittent claudication symptoms (walking distance) in patients with LEAD are limited. The ESC guidelines [I] state that, given the impact on intermittent claudication, calcium antagonists or ACEI/ARB are preferred for patients with PAD and arterial hypertension, due to their ability to dilate peripheral arteries. A randomized clinical trial showed that verapamil extended the walking distance in patients with LEAD [66]. Similar benefits were achieved in one randomized trial with ramipril [67]. The results of trials using ACE inhibitors are controversial, since of the six trials with ACE inhibitors compared to placebo which was included in the meta-analysis in 2013 [68], an improvement in the walking distance was observed in three trials with ramipril, two of which were subsequently retracted due to unreliable data [69], while three trials with other ACE inhibitors (captopril, cilazapril, perindopril), no benefits were achieved. In the new meta-analysis, which included only the four trials remaining after the two studies on ramipril had been retracted, no improvement of the walking distance was found [70].

Nebivolol was also hailed as a beta-adrenolytic drug with additional vasodilatory action [I], but the evidence of the potential superiority of vasodilatory beta-adrenolytics over the conventional beta-adrenalitis in patients with LEAD is very limited. Metoprolol and nebivolol were compared in a double-blind randomized clinical trial with 128 adrenolytic treatment-naïve patients suffering from intermittent claudication and arterial hypertension [7I]. After 48 weeks of treatment, both drugs were found to be well-tolerated, exercising similar hypotensive effect and improving the maximum walking distance and $A B I$ in both groups, without significant differences between the groups. Nebivolol was found to be superior only in terms of improving the walking distance until pain occurred.

The recommendations on the treatment of arterial hypertension in patients with LEAD are outlined in Table 5.

\subsection{Anticoagulation treatment}

Anticoagulation treatment is an important aspect of pharmacotherapy in patients with LEAD, aimed at both reducing the global cardiovascular risk and the risk of limb-related incidents, and improving the treatment outcomes after percutaneous or surgical revascularization.

Platelets play a crucial role in the pathogenesis of atherosclerotic and thrombotic complications in the arterial system, and the inhibition of platelet activation and aggregation is the basic mechanism of prevention of adverse cardiovascular events. The antiplatelet agent of choice is acetylsalicylic acid (ASA) which inhibits cyclooxygenase activity and thromboxane A2 synthesis. Other antiplatelet drugs include platelet P2YI2 receptor inhibitors which inhibit ADP-induced platelet activation, thienopyridine derivatives (ticlopidine, later replaced with clopidogrel and prasugrel), and ticagrelor which unlike clopidogrel is a non-thienopyridine, reversible inhibitor of the $P 2 Y \mid 2$ receptor. Among the currently used $P 2 Y \mid 2$ receptor inhibitor, large trials on patients with LEAD studied clopidogrel and ticagrelor, while prasugrel has thus far been studied mainly in patients with coronary artery disease. The new oral antiplatelets are PAR-I thrombin receptor antagonists (e.g. vorapaxar and atopaxar) which inhibit thrombin-induced platelet activation [72]. Among those agents, vorapaxar was studied in large clinical trials on patients with LEAD. PAR-I thrombin receptor antagonists are currently not available in Poland.

Anticoagulation drugs, including vitamin $\mathrm{K}$ antagonists (VKAs; warfarin and acenocoumarol) and direct oral anticoagulants (DOACs) other than vitamin $\mathrm{K}$ antagonists, are used mainly in patients with conventional indications for chronic oral anticoagulation, such as acenocumarol or venous thromboembolism; however, data from the recent clinical trials also indicate a potential role of rivaroxaban combined with ASA in a broader population of patients with LEAD, who do not have conventional indications for chronic oral anticoagulation.

Various anticoagulation therapy strategies are available, but the choice between specific strategies is not always clear [73]. The key international guidelines differ slightly in terms of indication for treatment and the choice of specific drugs [I-3]. Furthermore, no single strategy will be optimal for all disease stages and patient subgroups (i.e. asymptomatic LEAD, intermittent claudication, critical limb ischemia, patients after intravascular or surgical revascularization). In part due to those discrepancies and ambiguities, the anticoagulation treatment remains underused in patients with LEAD despite the high risk of atherosclerotic and thrombotic events in this patient group [73].

\subsection{Asymptomatic lower extremity artery disease}

In two randomized, placebo-controlled clinical trials, no benefits were found from using ASA in asymptomatic LEAD [74, 75]. One of the trials was conducted in a general population with $A B I<0.95$, the other in a population of diabetic patients with $A B I<1.0$. No benefits from using ASA were also found in subgroups with $A B I<0.9$, although those studies might not have had the sufficient statistical power to detect benefits from using $A S A$ in patients with lower $A B I$ values [73]. On the basis of the results of those trials, the 
ESC guidelines on the management of PAD [I] stated that antiplatelet therapy is indicated for patients with symptomatic LEAD or after revascularization (class of recommendation/level of evidence: I $A / C$ ), but is not routinely indicated in patients with asymptomatic LEAD who do not have indications for antiplatelet therapy due to another arterial disease (e.g. coronary artery disease). Authors of other guidelines believe, however, that antiplatelet therapy should be considered also for patients with asymptomatic $\operatorname{LEAD}(A B I \leq 0.9)$, given the generalized nature of atherosclerosis and high cardiovascular risk in those patients (class of recommendation/ /level of evidence: $\mathrm{Ila} / \mathrm{C}$ in $2016 \mathrm{AHA} / \mathrm{ACC}$ guidelines) [2]. Given the absence of evidence of the benefits of antiplatelet therapy in patients with asymptomatic LEAD, it is also unclear whether patients with masked LEAD (see 3.2) should be classified as patients with asymptomatic or symptomatic disease.

\subsubsection{Symptomatic lower extremity artery disease \\ Single antiplatelet drug therapy}

Acetylsalicylic acid - it is believed that the strongest evidence of the benefits of using ASA in symptomatic LEAD has been provided by the Antithrombotic Trialists Collaboration meta-analysis which showed that in 6, 200 patients with intermittent claudication, taking ASA significantly reduced the incidence of major adverse cardiovascular events (MACE; cardiovascular deaths, and non-fatal myocardial infarction and stroke), as compared to the control group [76]. Also, in the later randomized CLIPS trial which enrolled patients with asymptomatic LEAD or intermittent claudication $(n=$ $366,77 \%$ of patients with intermittent claudication), using ASA significantly reduced the incidence of MACE or critical limb ischemia [77]. However, some meta-analyses did not find significant benefits from using ASA in patients suffering mainly from symptomatic PAD [78].

Clopidogrel - in the post hoc analysis of the data from CAPRIE trial, it was found that in the subgroup of 6,452 patients with clinically overt LEAD clopidogrel significantly reduced cardiovascular mortality and the incidence of MACE as compared to ASA [79]. Indirect comparisons of various regimens using the meta-analysis of clinical trials also show the superiority of clopidogrel over ASA [80]. Based on the data from CAPRIE trial, the ESC guidelines considered clopidogrel to be more preferable than ASA, however, with a low class of recommendation and level of evidence (Ilb/B) [I], while the other major international guidelines $[2,3]$ do not prefer clopidogrel over ASA as the antiplatelet drug of choice for symptomatic LEAD monotherapy.

Ticagrelor - the randomized EUCLID trial compared ticagrelor with clopidogrel in 13,885 patients with symptomatic LEAD, finding no difference in the incidence of MACE or major bleeding [8I]. Treatment with ticagrelor was related to a significantly higher incidence of stroke, and also more frequent termination of treatment.

\section{Dual antiplatelet therapy}

It is believed that there is no direct evidence of the superiority of dual antiplatelet therapy (DAPT) with clopidogrel and ASA over ASA alone in patients with LEAD [82]. Dual antiplatelet therapy with clopidogrel and ASA was compared to ASA alone in CHARISMA trial. In the subgroup of patients with LEAD, using DAPT reduced the incidence of myocardial infarction, without affecting the overall incidence of MACE, and also increased 2 -fold the incidence of minor bleeding, without affecting the incidence of major, fatal and moderate bleeding [83].

The comparison of PAR-I thrombin receptor antagonist vorapaxar with placebo (in both groups, in combination with standard antiplatelet therapy) in the subgroup of patients with symptomatic LEAD in TRACER trial failed to demonstrate a significant reduction of the incidence of ischemic events, peripheral revascularization and amputations by that antiplatelet agent [84]. In larger TRA2 ${ }^{\circ}$ P-TIMI 50 trial, in the subgroup of patients with symptomatic LEAD, vorapaxar failed to reduce the risk of MACE but significantly reduced the risk of acute limb ischemia and peripheral revascularization as compared to placebo (in both groups in combination with standard antiplatelet therapy), however, at the cost of the increased bleeding risk $[85,86]$.

\section{Dual antiplatelet therapy in patients with lower extremity artery disease and co-occurring coronary artery disease}

The co-occurrence of LEAD and coronary artery disease is related to worse prognosis, and the presence of LEAD in patients might be an argument for a prolonged DAPT. In PRODIGY trial, which compared different durations of DAPT (clopidogrel and ASA) after coronary artery stenting, DAPT prolonged to 24 months reduced the risk of MACE in the subgroup of patients with co-occurring LEAD, as compared to a 6-month DAPT; however, for the entire group, no evidence of superiority of prolonged DAPT was found [87, 88]. PEGASUS-TIMI 54 trial assessed prolonged use of ticagrelor in the dose of $90 \mathrm{mg}$ or $60 \mathrm{mg}$ bid, combined with a low dose of ASA, in stable patients who had suffered from a myocardial infarction ( $1-3$ years prior) [89]. In the subgroup of patients with the concomitant LEAD, ticagrelor was most beneficial in terms of reducing the incidence of MACE, and also significantly reduced the risk of major adverse events in the limb (acute limb ischemia and peripheral revascularization) [90]. The 
ESC guidelines on the management of PAD [I] state that long-term treatment with ticagrelor combined with low-dose ASA may be considered in patients with LEAD who had suffered from a myocardial infarction more than 3 years prior (no class of recommendation specified).

Both the long-term use of ticagrelor combined with ASA after a heart attack in PEGASUS-TIMI 54 trial, and the prolonged DAPT with clopidogrel and ASA after acute coronary syndrome and/or coronary artery stenting, increased the incidence of major bleeding $[89,91]$. The decision on prolonging DAPT must include a careful assessment of the risk of both ischemic events and bleeding. The duration of DAPT in patients with coronary artery disease and concomitant LEAD, who are receiving DAPT for acute coronary syndrome and/or percutaneous coronary intervention, should generally conform to the current guidelines on DAPT [92].

\section{Combined antiplatelet and anticoagulation therapy}

Conventional anticoagulation therapy does not play an important role for patients with symptomatic LEAD who have no other confirmed indications for such treatment, such as atrial fibrillation or venous thromboembolism. The efficacy of warfarin or acenocumarol (with the target values of the international normalized ratio [INR] of prothrombin time of 2.0-3.0) combined with antiplatelet therapy, as compared to antiplatelet therapy alone in patients with PAD was assessed by WAVE trial. The trial failed to demonstrate the superiority of the combined antiplatelet and anticoagulation therapy in terms of MACE prevention; on the other hand, this type of treatment increased 3-fold the incidence of life-threatening bleeding [93]. An interesting therapeutic option is combining antiplatelet therapy with small doses of new oral anticoagulants. The first observations suggesting a beneficial effect of this kind of combined treatment originate from the studies on the subgroups of patients who suffered from acute coronary syndrome and received small doses of new oral anticoagulants in addition to antiplatelet therapy (ATLAS ACS 2 TIMI 5I trial) [94].

The recent COMPASS trial assessed the new strategy of combined antiplatelet and anticoagulation therapy based on combining ASA with a small dose of DOAC, which was compared to the use of ASA alone and NOAC alone in patients with confirmed stable circulatory disease [95]. Since the results of COMPASS trial suggest new opportunities for combined anticoagulation therapy in patients with LEAD; because those results could not have been included even in the latest 2017 ESC guidelines on the management of PAD, the authors of this document have decided to discuss them in detail herein due to their potential impact on the future practice of management of patients with LEAD.

\section{COMPASS trial}

COMPASS was a large, multi-centre, randomized trial which compared the combined treatment with ASA (100 mg/day) and small dose of rivaroxaban $(2.5 \mathrm{mg}$ bid), and rivaroxaban alone (5 $\mathrm{mg}$ bid) or ASA alone ( $100 \mathrm{mg} /$ day), in over 27,000 patients with stable coronary artery disease or PAD. The trial was terminated after an average of 23 months of observation due to the superiority of the combined treatment with ASA and rivaroxaban which significantly reduced the incidence of the composite endpoint of cardiovascular deaths, myocardial infarctions and strokes, and the reduction of cardiovascular mortality and overall mortality [95].

In the prospectively planned analysis of a subgroup of 7,470 patients with PAD (LEAD or carotid artery disease) it was determined that the combined treatment with ASA and rivaroxaban significantly reduced the incidence of the aforementioned composite endpoint, as compared to ASA alone (reduction of risk by $28 \%$ ), and significantly reduced the incidence of major limb-related events, including amputations (reduction of risk by $46 \%$ ) [96]. The overall risk of amputations due to vascular causes was reduced by $60 \%$, and the risk of major amputations was reduced by $70 \%$ compared to the group treated with ASA only. The median treatment period was 21 months. The inclusion criteria for patients with LEAD included: previous percutaneous or surgical intervention, history of amputation, or intermittent claudication in patients with objectively documented LEAD (ABI $<0.9$ or arterial stenosis $\geq 50 \%)$. Major limb-related incidents were defined as acute limb ischemia, severe chronic limb ischemia requiring vascular intervention, or amputation. The results in the subgroup with LEAD were similar to the entire group of patients with PAD. Monotherapy with rivaroxaban failed to reduce the incidence of the primary endpoint compared to ASA but reduced the incidence of major limb-related incidents, as well as the incidence of amputations. Rivaroxaban, both in monotherapy and in combination with ASA, increased the incidence of major bleeding, mainly from the gastrointestinal tract, but no increase of the incidence of fatal bleeding, intracranial hemorrhages and within the major organs.

Also, the results of a separate analysis were published concerning the incidence of major limb-related events in 6, 39I patients with LEAD who were enrolled in COMPASS trial [97]. Compared to the treatment with ASA alone, the combined treatment with rivaroxaban and ASA reduced the incidence of major limb-related events by $43 \%$, all amputations by $59 \%$ and peripheral vascular interventions by $24 \%$. The oc- 
currence of a major limb-related event was related to poor prognosis (8.3\% risk of death within I year; $20.5 \%$ risk of amputation within I year). The benefits of treatment with rivaroxaban were offset by the increased risk of major bleeding, although without a significant increase in the incidence of severing and fatal bleeding. The authors of the editorial note [98] pointed out that due to the fact that the absolute reduction of the risk of major limb-related events was more or less equal to the absolute increase of the risk of major bleeding, the assessment of the benefits to risk ratio related to the addition of rivaroxaban might be difficult. The risk of major limb-related events was highest in patients with a history of amputations or vascular interventions (3.8\%), followed by patients with symptomatic LEAD but without prior amputations or vascular interventions (1.73\%). The lowest risk was observed for patients with asymptomatic LEAD $(0.5 \%)$. Thus, it appears that the benefits to risk ratio may be most favourable for patients with a history of prior amputations and vascular intervention, and the least favourable for patients with asymptomatic LEAD. Given the overall reduction of the risk of MACE in COMPASS trial, it was also concluded that the addition of rivaroxaban may be more beneficial to patients with concomitant coronary artery disease, especially those who had a previous heart attack.

\subsubsection{Patients with lower extremity artery disease} who underwent intravascular or surgical

\section{peripheral revascularization}

\section{Antiplatelet and anticoagulation therapy after surgical revascularization of LEAD}

Acetylsalicylic acid compared to placebo - the meta-analysis (952 patients) revealed that the patency of the peripheral bypass was significantly improved in the ASA group compared to placebo. The beneficial therapeutic effect was particularly visible for bypasses made with synthetic materials. The incidence of amputations and bleeding and the survival rate were similar regardless of whether ASA was used or not [99].

\section{Acetylsalicylic acid compared to oral anticoagu-} lants - using VKAs after surgical bypassing of peripheral arteries is not well established in the clinical practice. In the trial titled "Dutch Bypass Oral Anticoagulants or Aspirin Study", a 2-year observation failed to demonstrate differences in the patency of the bypasses, mortality and incidence of amputations between the group receiving ASA (or ASA and dipyridamole) and the group receiving VKAs. The analysis of subgroups revealed, however, that in the group with a venous bypass, VKAs prolonged the patency of the bypass. The major bleeding risk was 2 times higher among the patients receiving VKAs [100]. Another study showed that combined therapy with VKA and ASA in the post-operative period did not significantly impact the patency of the bypasses as compared to the patient group receiving only ASA, but increased the major bleeding risk 2 -fold. The only group who benefited from the combined VKA+ASA therapy were the patients who had had a synthetic bypass with $6 \mathrm{~mm}$ diameter implanted. The benefit was not observed in patients with the bypass with $8 \mathrm{~mm}$ diameter [ $\mathrm{IOI}]$. Also, the use of dalteparin combined with ASA failed to benefit the patients who had undergone surgical revascularization due to LEAD [102]. The benefits from using warfarin and ASA compared to ASA alone were observed in a small study on patients with venous bypasses who were in the high bypass occlusion risk group (suboptimal bypass, poor reception of blood from the bypass, reoperation). The combined treatment was also related to increased incidence of bypass patency and limb preservation but at the cost of increased incidence of hematomas [103]. DAPT was also assessed in comparison to the combined treatment with VKAs and clopidogrel in patients who had undergone femoral-popliteal bypass surgery. A significant difference was found in the patency of the bypasses in favour of the patients treated with VKAs and clopidogrel; the incidence of MACE did not differ between the groups. Also, in that study, the use of VKAs increased the incidence of bleeding [104].

Acetylsalicylic acid compared to dual antiplatelet therapy - the randomized trial CASPAR compared monotherapy (with ASA) with DAPD (ASA + clopidogrel) in patients who had undergone bypass and peripheral shunt surgery below the knee joint. No differences were found between the groups in terms of the incidence of the composite endpoint of bypass occlusion, repeated revascularization, limb amputation above the knee joint, and death. $A$ beneficial therapeutic effect of DAPT in terms of the endpoint specified above was found only in the prospectively defined subgroup of patients who had undergone femoral-popliteal bypass surgery with a synthetic bypass; no such benefits were found in patients with venous bypasses. At the same time, increased bleeding incidence was observed in the DAPT group, although the incidence of sever and fatal bleeding did not differ significantly between both groups [105].

\section{Antiplatelet/anticoagulation therapy after intravascular interventions due to LEAD}

Not much data is available on the efficacy and safety of various anticoagulation treatment regimens in patients who undergo intravascular interventions for LEAD. The current standard regimens after intravascular interventions in peripheral arteries are partially based on the results of studies assessing the regimens after coronary interventions. 
Currently, the guidelines recommend DAPT for at least I month after the intravascular intervention, regardless of the stent type (uncoated metal stent or drug-eluting stents) [I, 3]. In clinical trials, DAPT is typically administered for at least 30-60 days, also in studies with drug-coated balloons [106, 107], although sometimes it is used for much longer periods - for example, in IN. PACT SFA study, in half of the enrolled patients DAPT was continued for over a year [108]. As specified in the ESC guidelines [I], DAPT is often administered longer after stenting arteries below the knee, but there is no evidence to support this strategy. Once DAPT is ended, regardless of its duration, the standard procedure after an intravascular intervention is indefinite treatment with a single antiplatelet agent (ASA or clopidogrel).

In MIRROR study, it was found that the use of clopidogrel and ASA for 6 months reduced the frequency of repeated interventions as compared to ASA alone, but that benefit of DAPT was not maintained after 6 months from discontinuing clopidogrel (i.e. after a total of 12 months of observation). The authors of the study concluded that for the patients who are in a high restenosis risk group, who would potentially benefit most from a prolonged DAPT, long-term treatment may be considered ( $>6$ months); currently, decisions on prolonging DAPT are often made on a case-by-case basis [109]. Prolonging DAPT may also be considered in the event of a coronary artery disease co-occurring with LEAD (see above). The ESC guidelines on the management of PAD [I] state that in patients with LEAD who have undergone percutaneous revascularization below the groin, DAPT may be prolonged to more than I month if the patient previously (i.e. within the previous year) suffered from acute coronary syndrome and/ or underwent percutaneous coronary intervention, and also after stenting the last patent coronary artery, and in the event of a multi-vessel coronary artery disease with incomplete revascularization in diabetic patients.

Anticoagulants do not play any role in patients after intravascular interventions due to LEAD. Anticoagulation therapy was analyzed prospectively after percutaneous revascularization below the groin, finding no improvement of vascular patency, while the incidence of bleeding was significantly increased [1 I0].

\subsubsection{Summary - choosing the anticoagulation strategy}

The anticoagulation therapy options for patients with LEAD can be divided into three main clinical categories: asymptomatic patients $(A B I \leq 0.9$, without intermittent claudication), symptomatic patients (intermittent claudication), or patients undergoing intravascular or surgical revascularization. The main clinical trials related to anticoagulation therapy of patients with LEAD are summarized in Figure I, while the proposed strategies of management are illustrated in Figure 2.

The recommendations on anticoagulation therapy of patients with atherosclerotic LEAD, without separate indications for chronic oral anticoagulation, are outlined in Table 8.

\section{Asymptomatic lower extremity artery disease}

In this patient group, treatment with the only single antiplatelet drug should be considered (ASA or clopidogrel). No clear evidence of the benefits of using ASA compared to placebo have been obtained in patients with asymptomatic LEAD, hence the difference of opinion between the experts on the indications for antiplatelet treatment in this group. The ESC guidelines do not recommend using antiplatelet agents in this group (class of recommendation/level of evidence: III/A) [I], while the $2016 \mathrm{AHA} / \mathrm{ACC}$ guidelines state that antiplatelet therapy is reasonable also in patients with asymptomatic LEAD (class of recommendation/ /level of evidence: Ila/C for patients with $A B I \leq 0.9$ ) [2]. This opinion was reiterated in more recent studies by American experts [73]. Treatment with ASA may be considered especially in patients with co-occurring atherosclerotic lesions in other arterial beds. Indications for treatment with ASA may also arise from the co-occurring symptomatic coronary artery disease, or cerebrovascular disease (history of brain stroke or transient ischemic attack [TIA]).

\section{Symptomatic lower extremity artery disease}

In this patient group, antiplatelet therapy is clearly recommended (class of recommendation I in all major guidelines) to reduce the risk of cardiovascular events. Treatment with only one antiplatelet agent may be considered, choosing between ASA or clopidogrel; recently, in view of the results of COMPASS trial, also combined anticoagulation therapy with ASA and a small dose of rivaroxaban may also be put into consideration. On the basis of the data from CAPRIE study, which found that clopidogrel was more beneficial than ASA to patients with LEAD, the authors of ESC guidelines [I] have concluded that clopidogrel may be the drug of preference (class of recommendation/level of evidence: $\mathrm{Ilb} / \mathrm{B}$ ); this opinion was shared by the authors of other guidelines: in the $2016 \mathrm{ACC} / \mathrm{AHA}$ guidelines [2], both drugs have identical class of recommendation/level of evidence (I/A), and the 2015 guidelines of the Society of Vascular Surgery [3] also do not specify preference for clopidogrel (ASA — I/A, clopidogrel as an alternative agent $-\mathrm{I} / \mathrm{B})$.

On the basis of the result of COMPASS study, an alternative strategy for anticoagulation treatment 


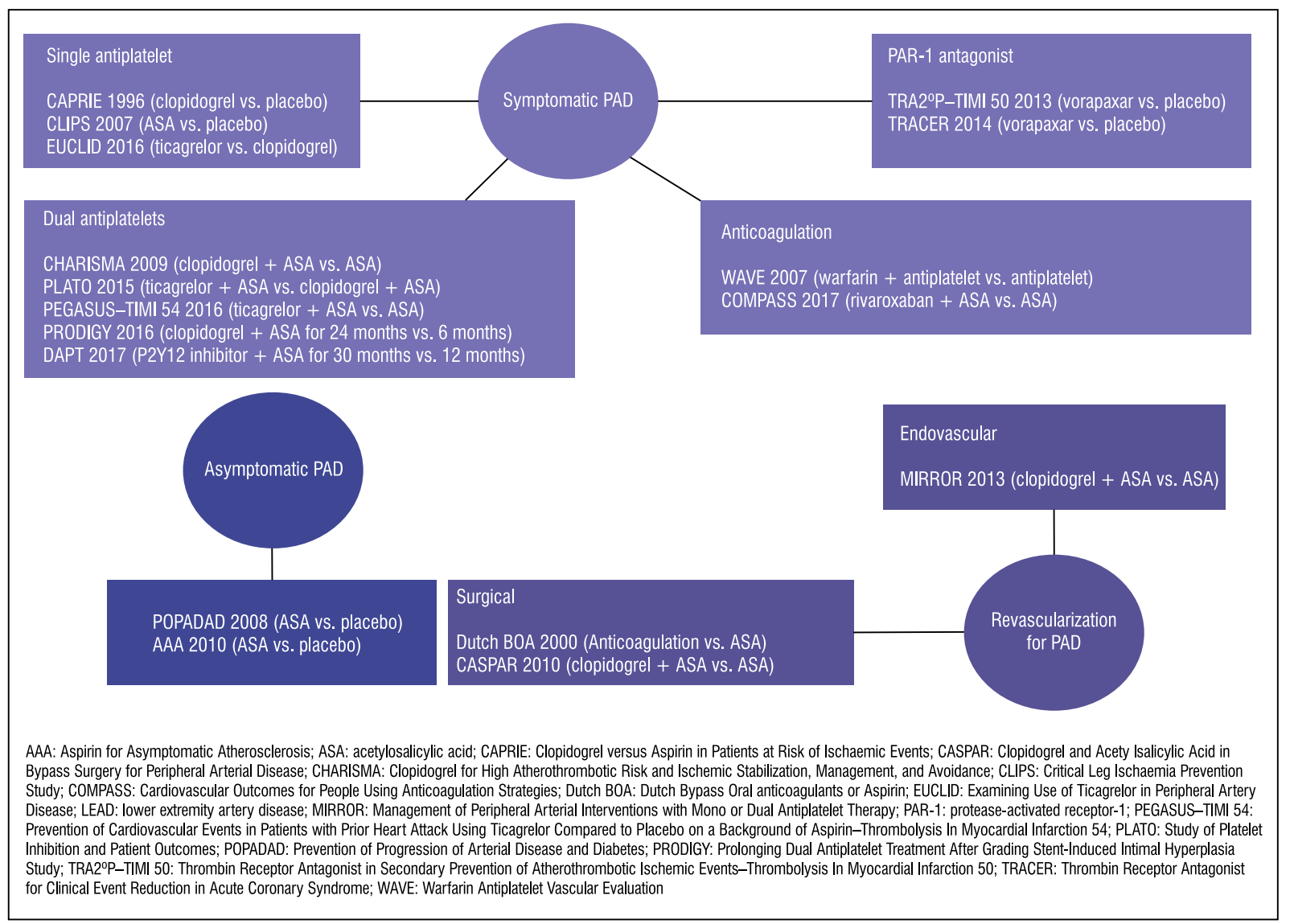

Figure I. Main clinical trials related to anticoagulation therapy of patients with lower extremity artery disease [73]

in this group may be based on ASA combined with a small dose of rivaroxaban. Given the reduction of the MACE risk, both clopidogrel in CAPRIE study and the combination of ASA and a small dose of rivaroxaban in COMPASS study proved more efficient in patients with LEAD than ASA alone. However, a reduction of the risk of major adverse events in the limb, including amputation, was observed only for the combination of ASA and a small dose of rivaroxaban; there is no evidence of the similar effect of ASA or clopidogrel alone. The absolute reduction of the risk of MACE and major adverse events in the limb in COMPASS study was I.54\% per year (NNT 58) [73], whereas the absolute reduction of the risk of MACE in CAPRIE study was I. I5\% per year (NNT 87) [79]. However, there is no direct comparison available between the small dose of rivaroxaban ( \pm ASA) and clopidogrel in patients with LEAD. Taking into consideration the increase of the major bleeding risk, the absolute reduction of the composite incidence of MACE, major adverse events in the limb, fatal bleeding and symptomatic bleeding within the major organs (net clinical benefit) in COMPASS trial was $1.43 \%$ per year (NNT 70) [73]. In the
CAPRIE study, clopidogrel proved safer than aspirin in terms of bleeding [79]. Considering the use of ASA and a small dose of rivaroxaban in patients with symptomatic LEAD, the bleeding risk must be weighed carefully, all the more so that the patients in the high bleeding risk group were excluded from COMPASS study. Summing up, it appears that both strategies (clopidogrel and the combination of ASA and a small dose of rivaroxaban) may be considered as potentially more beneficial than ASA alone in patients with symptomatic LEAD.

Other possible anticoagulation strategies are not relevant for this patient group. Ticagrelor is not recommended, since in EUCLID study it did not prove superior to clopidogrel. Similarly, there are no indications for DAPT in patients who do not undergo revascularization due to LEAD, because CHARISMA study failed to demonstrate a clear superiority of the combined treatment with clopidogrel and ASA over single antiplatelet regimen. Vorapaxar is not available in Poland, since according to the clinical trials conducted thus far, vorapaxar's value when combined with standard antiplatelet therapy remains unclear and requires further study (in TRA2 ${ }^{\circ}$ P-TIMI 50 study, a reduction 


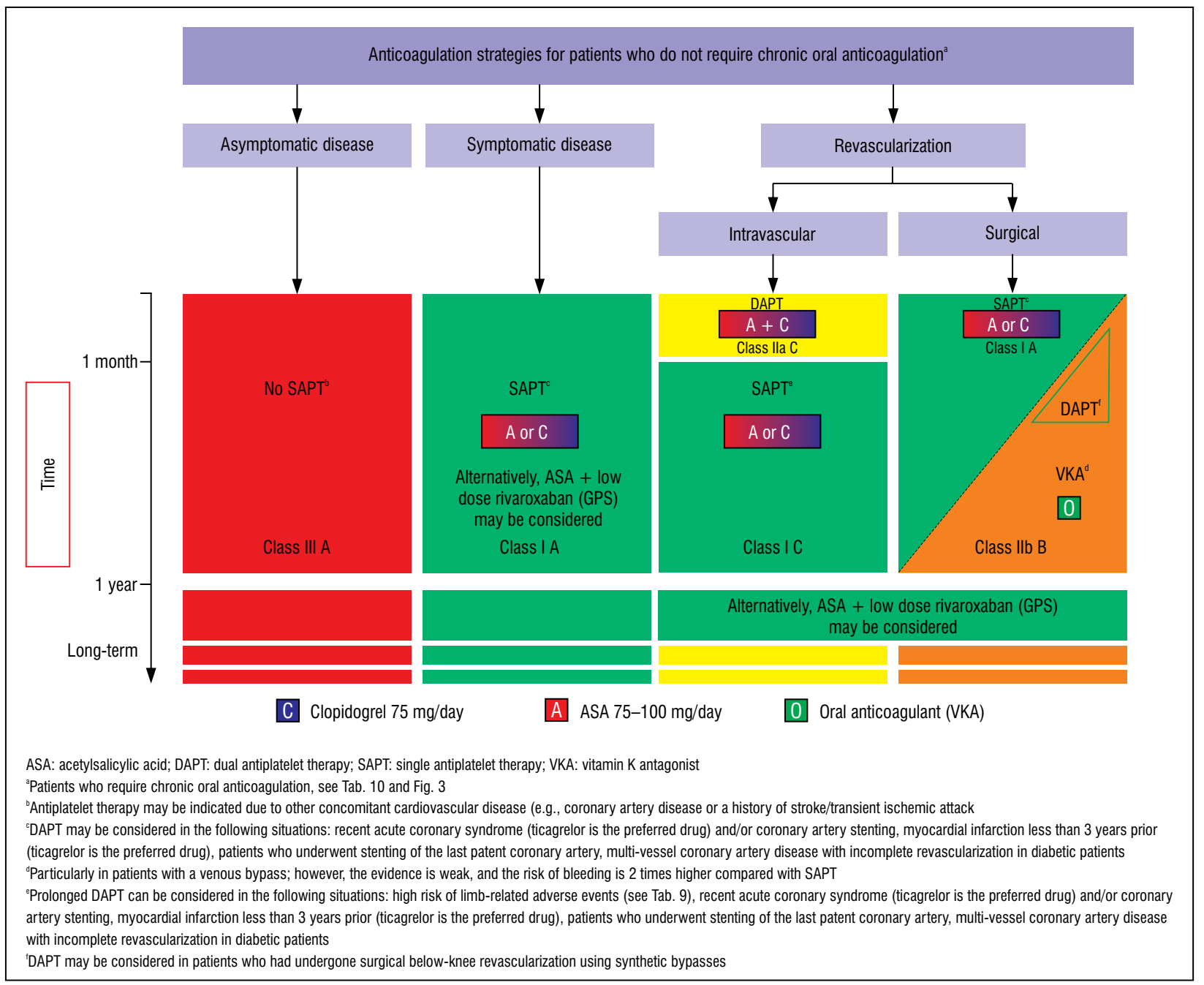

Figure 2. Anticoagulation strategies for patients with lower extremity artery disease (modified according to [I, 73])

of the risk of acute limb ischemia and the incidence of peripheral revascularizations was shown, but at the cost of increased bleeding risk and without impact on MACE). Conventional anticoagulation therapy (with VKAs or NOACs in standard dosing regimens) should not be used to reduce the risk of cardiovascular/ischemic events in this patient group since no evidence was found of the benefits of such treatment [2, 3, 93].

Patients with LEAD and concomitant coronary artery disease - a separate group is formed by the patients with a history of the recent acute coronary syndrome and/or percutaneous coronary intervention, which should be treated with DAPT with clopidogrel or ticagrelor and ASA. The indication for DAPT arises from coronary artery disease, rather than LEAD. The previous standard therapy involved clopidogrel and ASA. In the current ESC guidelines on the management of patients with ACS, the newer P2YI 2 receptor inhibitors (ticagrelor and prasugrel, and only ticagrelor in patients undergoing conservative treatment) are preferred over clopidogrel [92]. On the basis of the results of PEGASUS-TIMI 54 study, long-term treatment with ticagrelor combined with a small dose of ASA may be considered for patients with LEAD after a history of myocardial infarction less than 3 years prior [I]. For patients with LEAD, prolonged DAPT may also be considered after acute coronary syndrome and/or stenting of coronary arteries. However, both strategies involve an increased risk of major bleeding, hence a careful assessment is necessary for the risk of both ischemic events and bleeding (Table 9). The duration of DAPT in patients with coronary artery disease and concomitant LEAD, who are receiving DAPT for acute coronary syndrome and/or percutaneous coronary intervention, as well as the choice of the P2Y 2 receptor inhibitor (ticagrelor or clopidogrel), should generally conform to the current guidelines on DAPT [92]. Following the completion of DAPT, patients in this group receive a single antiplatelet drug (ASA or clopidogrel) indefinitely. 
Table 8. Anticoagulation therapy (antiplatelet and antithrombotic) in patients with atherosclerotic lower extremity artery disease

$\begin{array}{ccc}\text { Recommendation } & \begin{array}{c}\text { Class } \\ \text { of recommendation (quality) }\end{array} \\ \text { of evidence }\end{array}$

\section{Asymptomatic LEAD}

Due to the lack of confirmed benefits, antiplatelet therapy is not routinely indicated for patients with isolated asymptomatic LEAD

III A

\section{Symptomatic LEAD}

Long-term SAPT is recommended for patients with symptomatic LEAD

Preference of clopidogrel over ASA may be considered

Instead of SAPT, a combined treatment with ASA and small dose of rivaroxaban ${ }^{\mathrm{b}}$ may be considered, especially in patients with high risk of ischemic events in the limb $b^{c}$, provided that the bleeding risk is low

DAPT is not recommended in patients who are not undergoing revascularization for LEAD

Oral anticoagulants in therapeutic doses are not recommended in patients who are not undergoing revascularization for LEAD and who have no other indications for long-term oral anticoagulation therapy

DAPT (ASA + clopidogrel or ticagrelor) may be considered in patients with LEAD who have indications for DAPT due to coronary artery disease ${ }^{d}$

\begin{tabular}{|c|c|}
\hline I & A \\
\hline Ilb & B \\
\hline
\end{tabular}

\section{GPS}

\begin{tabular}{|c|c|}
\hline III & B \\
\hline III & B \\
\hline IIb & B \\
\hline
\end{tabular}

\section{Patients who underwent revascularization for LEAD}

Long-term SAPT is recommended for all patients who underwent revascularization

SAPT is recommended after surgical revascularization

VKAs may be considered (without antiplatelet therapy) after surgical revascularization in individual cases, especially in patients with venous bypasses, if the bleeding risk is low compared to the risk of bypass occlusion

DAPT may be considered after surgical revascularization in patients with synthetic bypasses implanted below the knee

DAPT (ASA + clopidogrel) should be considered for at least I month after intravascular revascularization

A longer DAPT may be considered after intravascular revascularization in patients with a high risk of an ischemic event in the limb ${ }^{c}$

After both surgical and intravascular revascularization, DAPT (ASA + clopidogrel or ticagrelor) may be considered in patients with LEAD who have indications for DAPT due to coronary artery disease ${ }^{d}$

After both surgical and intravascular revascularization, a combined treatment with ASA and a small dose of rivaroxaban ${ }^{\mathrm{b}}$ may be considered, especially in patients with a high risk of ischemic events in the limb ${ }^{c}$, provided that the bleeding risk is low

\begin{tabular}{|c|c|}
\hline I & C \\
\hline I & A \\
\hline Ilb & B \\
\hline Ilb & B \\
\hline Ila & C \\
\hline Ilb & B \\
\hline Ilb & B \\
\hline
\end{tabular}

ASA: acetylsalicylic acid; DAPT: dual antiplatelet therapy; LEAD: lower extremity artery disease; SAPT: single antiplatelet therapy; VKA: vitamin K antagonist. alf there is no concomitant circulatory disease requiring antiplatelet therapy (e.g. coronary artery disease or a history of stroke/transient ischemic attack of the Central Nervous System)

${ }^{b}$ High risk of an adverse event in the limb can be defined as a synthetic bypass, bypass below the knee, suboptimal bypassing effect, poor blood reception from the bypass, widespread arterial lesions, or tissue loss [73]

'Recent acute coronary syndrome (ticagrelor is the preferred drug) and/or stenting of coronary arteries, heart attack $<3$ years prior (ticagrelor is the preferred drug), status post-stenting of the last patent coronary artery, multi-vessel coronary artery disease in diabetic patients who have undergone incomplete revascularization

\section{Revascularization due to lower extremity artery disease}

Surgical revascularization - for patients who have undergone surgical revascularization, various strategies may be considered, including a single anti- platelet regimen (ASA or clopidogrel), DAPT, VKAs, and recently, given the results of COMPASS study, also the combined anticoagulation therapy with ASA and a small dose of rivaroxaban. Given the results of CASPAR study, it appears that for the entire population of patients who 
Table 9. Risk factors of ischemic events, bleeding risk factors and increased risk factors for limbs which should be taken into consideration in making decisions on anticoagulation therapy in patients with atherosclerotic lower extremity artery disease [73]

\begin{tabular}{|l|l|l|}
\hline Risk of ischemic events $\uparrow$ & Bleeding risk $\uparrow$ & Synthetic bypass \\
\hline History of heart attack & Anticoagulation treatment & Bypass below the knee \\
\hline Diabetes & History of bleeding & Suboptimal bypassing effect \\
\hline Old age & Old age & Poor reception of blood from the bypass \\
\hline Chronic kidney disease & Chronic kidney disease & Widespread arterial lesions \\
\hline Heart failure & Anaemia & Tissue loss \\
\hline Smoking & Low body weight & \\
\hline
\end{tabular}

have undergone surgical revascularization, DAPT is not clearly superior over a single antiplatelet regimen. In the study, the benefits of DAPT were observed after bypass surgery below the knee in the patients with synthetic bypasses; no such benefits were found in patients with venous bypasses. The evidence of the benefits of VKA therapy is also limited and obtained mainly from patients with venous bypasses.

The ESC guidelines [I] generally recommend single platelet regimen for this group (ASA or clopidogrel; class of recommendation/level of evidence $\mathrm{I} / \mathrm{A}$ ); alternative strategies include: I) treatment with VKAs of patients with venous bypasses (class of recommendation/ level of evidence: $\mathrm{llb} / \mathrm{B}$ ), although it is noted that the available evidence for anticoagulation therapy is weak and the bleeding risk increases twofold compared to antiplatelet agents; and 2) DAPT (ASA + clopidogrel) in patients with synthetic bypasses below the knee (class of recommendation/level of evidence: Ilb/B). The authors of the guidelines also conclude that for patients with a history of recent acute coronary syndrome and/ lor percutaneous coronary intervention (less than I year prior), and after the stenting of the last patent coronary artery, and also in the case of multi-vessel coronary artery disease with incomplete revascularization in diabetic patients, DAPT may be considered [I]. Other major guidelines [2, 3] recommend single antiplatelet regimen (ASA or clopidogrel) or DAPT as an alternative; VKAs are either not recommended [3] or considered to be of uncertain usefulness [2].

In general, intensifying the anticoagulation therapy in this group should be considered firstly for the patients exposed to high risk of major adverse events in the limbs, such as bypass thrombosis or amputation. The risk factors related to the increased limb-related risk include synthetic bypass, bypass below the knee, the suboptimal effect of bypassing, poor blood reception from the bypass, widespread lesions in arteries, and tissue loss (Table 9) [73]. Among the three available strategies (ASA + small dose of rivaroxaban, DAPT or VKAs), the strongest evidence in terms of reducing the risk of major adverse events in the limbs of patients with LEAD have been acquired for the combined anticoagulation therapy with ASA and a small dose of rivaroxaban. This strategy has not yet been included in the major international guidelines, since the results of COMPASS study were published later, but can be found in the latest expert studies [73].

All regimens of the intensified anticoagulation therapy are related to increased bleeding risk compared to the single antiplatelet regimen. Thus, a careful assessment is necessary for the risk of both limb-related events and bleeding (Table 9).

\section{Intravascular revascularization (angioplasty with or without stenting)}

The guidelines generally recommend DAPT (ASA + clopidogrel; ESC class of recommendation/level of evidence: Ila/C) for $\geq I$ month (I-6 months according to MIRROR study [73]); after DAPT is completed, the patients in this group are treated indefinitely with single antiplatelet regimen (ASA or clopidogrel), although in light of the results of COMPASS study, also ASA combined with small dose of rivaroxaban may be considered. Prolonged DAPT may be considered for patients exposed to high risk of major adverse events in the limbs, and also in the case of indications arising from the concomitant coronary artery disease (e.g. recent history of the acute coronary syndrome and/or stenting of coronary arteries). The combined anticoagulation therapy with ASA and a small dose of rivaroxaban may also be more beneficial to patients in the group exposed to high risk of major adverse events in the limb. All regimens of the intensified anticoagulation therapy are related to increased bleeding risk. Thus, a careful assessment is necessary for the risk of both limb-related/ischemic events and bleeding (Table 9). 
There is insufficient evidence to differentiate the recommendations on the anticoagulation treatment regimen depending on the intervention type (conventional balloon angioplasty, drug-coated balloon angioplasty, metal stent implantation, drug-eluting stent implantation); the manufacturers' recommendations generally favour longer DAPT for therapies based on pharmacological technology - however, the aforementioned suggestions require confirmation in further studies on the revascularization of peripheral vessels.

\subsubsection{Antiplatelet and anticoagulation therapy in patients with lower extremity artery disease and separate indications for chronic oral anticoagula- tion therapy}

Patients with LEAD may have indications for chronic anticoagulation therapy arising from concomitant diseases rather than from LEAD. A typical example is the co-occurrence of atrial fibrillation. LEAD is one of the risk factors of atrial fibrillation, and this type of arrythmia affects between $10 \%$ and $20 \%$ of patients with PAD [I I I-I I3]. The co-occurrence of LEAD and atrial fibrillation is related to worse prognosis $[113,114]$.

Few data are available on the choice of specific anticoagulation therapy in patients with LEAD and indication for oral anticoagulation therapy, it is generally recommended to treat such patients only with an oral anticoagulant, without antiplatelet drugs (class of recommendation/level of evidence: $\mathrm{Ila} / \mathrm{B}$ in ESC guidelines) [I]. This applies to patients with symptomatic or asymptomatic LEAD, patients who have undergone surgical revascularization for LEAD, and patients who have undergone intravascular revascularization a long time before, or in the event of high bleeding risk. The ESC guidelines recommend that in such situations, the indication for chronic oral anticoagulation should be verified. Typical indications for anticoagulation include paroxysmal, persistent or permanent atrial fibrillation in patients with stroke risk factors, prosthetic heart valve or recent or recurrent venous thromboembolism (deep vein thrombosis and/or pulmonary embolism). In patients with LEAD and atrial fibrillation, anticoagulant is unequivocally recommended (class of recommendation/level of evidence: $\mathrm{l} / \mathrm{A}$ ) in patients with $\geq 2$ score on $\mathrm{CHA}_{2} \mathrm{DS}_{2}-\mathrm{VASc}$ scale (congestive heart failure; arterial hypertension; age $\geq 75-2$ points; diabetes, history of stroke or TIA - I point; vascular disease, including coronary artery disease or PAD; age 65-75, female sex), and should be considered (lla/B) for all other patients. It should be emphasized that the presence of LEAD accounts for I point on $\mathrm{CHA}_{2} \mathrm{DS}_{2}$-VASc scale and may affect the indication for chronic oral anticoagulation.
The decision to initiate an antiplatelet drug in patients who require long-term anticoagulation may depend on the concomitant coronary artery disease (recent acute coronary syndrome and/or percutaneous coronary intervention), or the need for intravascular revascularization as part of LEAD management. Combined treatment should be administered for the shortest possible time (at least I month is recommended), but decisions should be made on a case-by-case basis depending on the clinical indications and the bleeding risk [I]. In such situations, triple therapy (ASA, clopidogrel and anticoagulant) is advised against, with the exception of stenting arteries below the knee and complex lesions related to very high risk of thrombosis [ $I]$.

After intravascular revascularization, ASA or clopidogrel combined with an oral anticoagulant for at least I month should be considered, if the bleeding risk is low compared to the risk of stent/bypass occlusion (class of recommendation/level of evidence $\mathrm{lla} / \mathrm{C}$ in the ESC guidelines). After intravascular revascularization, only an oral anticoagulant should be considered if the bleeding risk is high compared to the risk of stent/bypass occlusion (class of recommendation/level of evidence $\mathrm{lla} / \mathrm{C}$ in the ESC guidelines). An oral anticoagulant combined with a single antiplatelet drug for longer than I month may be considered in patients with high risk of ischemic events, or in the case of another strong indication for long-term antiplatelet therapy (class of recommendation/level of evidence: Ilb/C; the ESC guidelines define it as prior stent thrombosis, acute limb ischemia during treatment with oral anticoagulant, and indications arising from the concomitant coronary artery disease: recent acute coronary syndrome, stenting of the last patent coronary artery, multi-vessel coronary artery disease with incomplete revascularization in diabetic patients [I]). Based on the same indications, also a combination of an oral anticoagulant and a single antiplatelet drug may be considered for patients from the group with high bleeding risk compared to stent/bypass occlusion risk. The proposed algorithm of management, based on the ESC guidelines [I], is illustrated in Figure 3. It is recommended to protect the stomach mucosa with a proton-pump inhibitor; the intensity of the oral anticoagulation must be carefully monitored. The target INR values for patients treated with VKAs is 2.0-2.5, with the exception of patients with the prosthetic mitral valve. Patients who receive NOACs combined with an antiplatelet drug should be treated with the lowest dose tested in the trials which have been the basis for the drug's registration for stroke prevention [115, II6].

The recommendations on anticoagulation therapy of patients with atherosclerotic LEAD and separate 


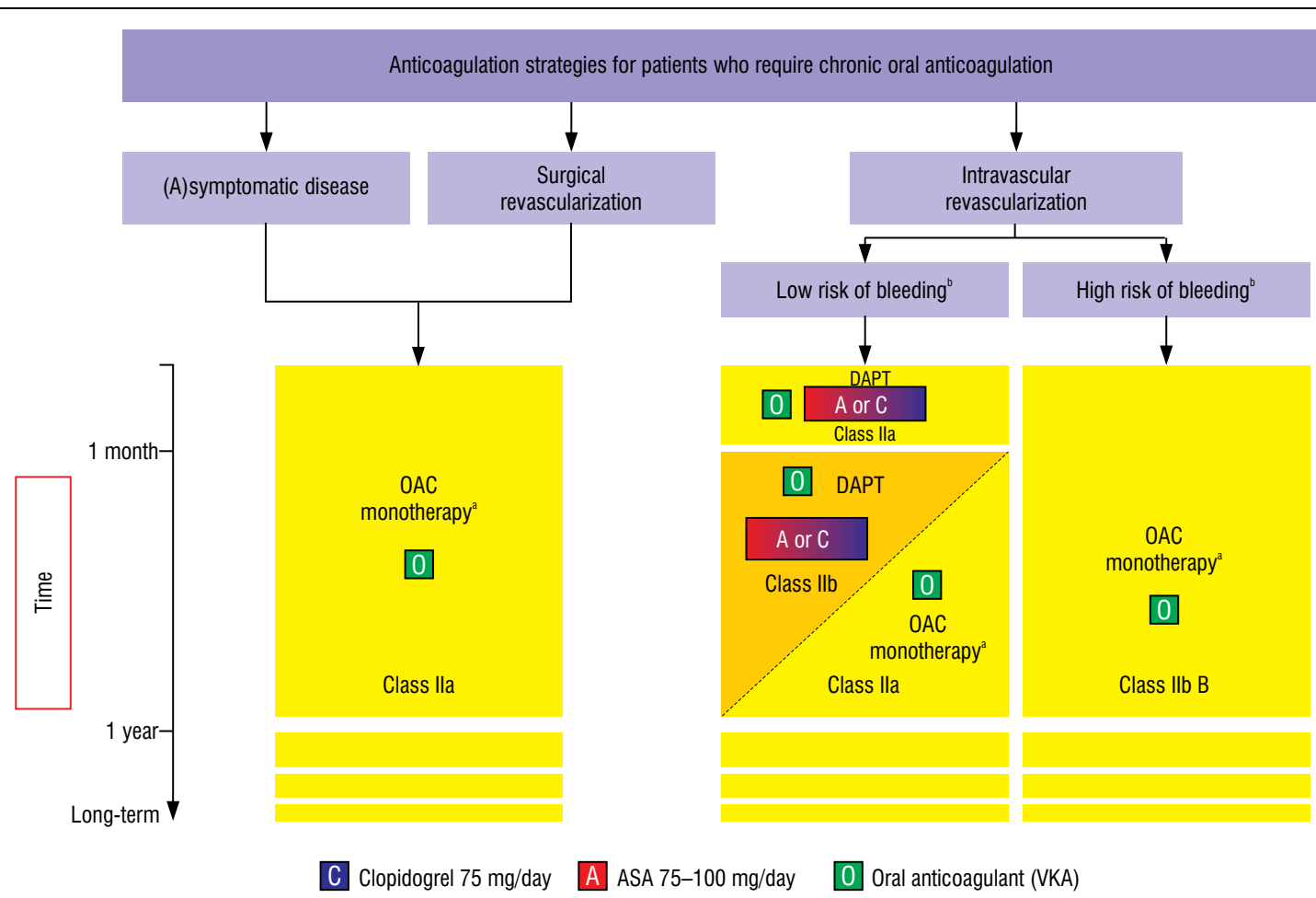

SA: acetylsalicylic acid; DAPT: dual antiplatelet therapy; LEAD: lower extremity artery disease; NOAC: novel oral anticoagulants other than vitamin K antagonists; OAC; oral anticoagulants; VKA: vitamin $\mathrm{K}$ antagonist

[DAPT may be considered in patients with high risk of ischemic events, defined as previous stent thrombosis, acute limb ischemia during treatment with oral anticoagulant or concomitant coronary artery disease (recent acute coronary syndrome, stenting of the last patent coronary artery, multi-vessel coronary artery disease with incomplete revascularization in diabetic patients)

${ }^{\text {bC }}$ ompared with the risk of stent/bypass occlusion

Figure 3. Anticoagulation therapy for patients with lower extremity artery disease who require chronic oral anticoagulation (modified according to [I])

indications for chronic oral anticoagulation are outlined in Table 10.

\subsection{Symptomatic treatment}

For patients with intermittent claudication, the key elements of therapy are the prevention of cardiovascular events and exercise training. If the patient's daily activities are significantly disturbed, revascularization should be considered (combined with exercise therapy; this also applies to the situations when activity is significantly reduced despite the exercise therapy and other treatment methods). Pharmacotherapy to improve LEAD symptoms is only supplementary.

It should be pointed out that the drugs used to reduce global cardiovascular risk do not significantly improve intermittent claudication. For this reason, for patients with intermittent claudication, pharmacotherapy to improve the LEAD symptoms is often based on drugs other than used in reducing the cardiovascular risk. Statins are an exception since a number of meta-analyses have shown a significant improvement of pain-free walking distance (PFWD) and maximum walking distance (MWD) in patients treated with statins [3।, II $]$ ]. Statins can also reduce the incidence of adverse events in the legs of patients with LEAD [34]. Limited data indicating an improvement of the walking distance have also been acquired for hypotensive drugs (ramipril, verapamil) and antiplatelet drugs (details - see Table 3).

It should also be emphasized that pharmacotherapy in intermittent claudication is not as efficient as exercise therapy or successful revascularization. The pharmacotherapy of intermittent claudication is also less efficient in patients who refuse to quit smoking and fail to adhere to exercise therapy. The objective of pharmacotherapy of claudication is to reduce the severity of LEAD symptoms and increase the walking distance for patients with intermittent claudication which affects the quality of life, particularly when modification of the risk factors and exercise therapy are unsuccessful and the patient is not eligible for revascularization, does not consent to such treatment, or there are contraindications for revascularization [I-3]. 
Table 10. Anticoagulation therapy for patients with lower extremity artery disease who require chronic oral anticoagulation

\begin{tabular}{|c|c|c|}
\hline Recommendation & $\begin{array}{c}\text { Class } \\
\text { of recommendation }\end{array}$ & $\begin{array}{l}\text { Level (quality) } \\
\text { of evidence }\end{array}$ \\
\hline \multirow{2}{*}{$\begin{array}{l}\text { For patients with LEAD and atrial fibrillation, OACs: } \\
\text { - are recommended for patients with } \geq 2 \text { score on } \mathrm{CHA}_{2} \mathrm{DS}_{2}-\mathrm{VASc} \text { scale } \\
\text { — should be recommended for all other patients }\end{array}$} & 1 & $A$ \\
\hline & Ila & B \\
\hline $\begin{array}{l}\text { For patients with LEAD and indication for OACs (e.g. atrial fibrillation, prosthetic heart } \\
\text { valve or venous thromboembolism), treatment only with OACs should be considered }\end{array}$ & Ila & B \\
\hline $\begin{array}{l}\text { For patients with LEAD and indication for OACs after surgical revascularization, } \\
\text { treatment only with OACs should be considered }\end{array}$ & Ila & C \\
\hline $\begin{array}{l}\text { For patients with LEAD and indication for OACs after intravascular revascularization, } \\
\text { SAPT (ASA or clopidogrel) combined with an oral anticoagulant for at least I month } \\
\text { should be considered, if the bleeding risk is low compared to the risk of stent/bypass } \\
\text { occlusion }\end{array}$ & Ila & C \\
\hline $\begin{array}{l}\text { For patients with LEAD and indication for OACs after intravascular revascularization, } \\
\text { treatment only with OACs should be considered, if the bleeding risk is low compared } \\
\text { to the risk of stent/bypass occlusion }\end{array}$ & Ila & C \\
\hline $\begin{array}{l}\text { A combination of OAC and SAPT (ASA or clopidogrel) for longer than I month may } \\
\text { be considered for patients with a high risk of ischemia, or with another strong indication } \\
\text { for long-term SAPT }\end{array}$ & Ilb & $C$ \\
\hline
\end{tabular}

ASA: acetylsalicylic acid; LEAD: lower extremity artery disease; OAC: oral anticoagulant; SAPT: single antiplatelet therapy

The $\mathrm{CHA}_{2} \mathrm{DS}_{2}$-VASc score is calculated as follows: congestive heart failure - I point, arterial hypertension - I point, age $\geq 75-2$ points, diabetes - I point, stroke -2 points, vascular disease — I point, age 65-74 — I point, female sex - I point

${ }^{a}$ Defined as prior stent thrombosis, acute limb ischemia during oral anticoagulation or concomitant coronary artery disease (recent acute coronary syndrome, status post-stenting of the last patent coronary artery, multi-vessel coronary artery disease with incomplete revascularization in diabetic patients)

A number of pharmacological agents have been assessed in the treatment of intermittent claudication of patients with LEAD. The most promising data, showing an increase in PFWD and MWD in randomized, controlled clinical trials, were acquired for cilostazol and naftidrofuryl [ I 18]; however, only the former is available in Poland. Other assessed agents, which have also been claimed to increase the walking distance in patients with intermittent claudication, include pentoxifylline, carnitine, propionyl-L-carnitine, prostanoids (prostaglandins 12 and E2), buflomedil, L-arginine, maidenhair tree (Ginkgo biloba) and sulodexide [1 17-120]. The ESC guidelines on the management of patients with LEAD emphasize however that only limited objective documentation of the effect is available, and the beneficial impact on the walking distance, if any, is usually minor to moderate, and varies considerably between patients [ I I 7]. Also, no additional benefits of those drugs are known when combined with exercise therapy and treatment with statins. Consequently, in the ESC guidelines [I], class of recommendation/level of evidence I / A/C was assigned only to exercise therapy and treatment with statins (for revascularization, class of recommendation/ /level of evidence Ila / B/C was assigned); no formal recommendations were formulated for other drugs. Among those other drugs, cilostazol and naftidrofuryl were identified as potentially useful. For other pharmacological agents, i.e. pentoxifylline, prostanoids, buflomedil, L-arginine and maidenhair tree (Ginkgo biloba), it was concluded that insufficient data from randomized, controlled clinical trials were available to recommend them to patients with intermittent claudication [1 19-122]. In the 2016 ACC/AHA guidelines [2], the use of cilostazol as an efficient drug improving the symptoms of LEAD and increasing the walking distance of patients with intermittent claudication was assigned class of recommendation/level of evidence I/A; naftidrofuryl was not included in the guidelines, as it is not available in the United States. The use of pentoxifylline was not recommended (class/level III/B). In the 2015 guidelines published by the Society of Vascular Surgery [3], cilostazol was recommended (class/level 2/A); if the drug is not tolerated or contraindicated, pentoxifylline was recommended as an alternative (class/level 2/B).

Cilostazol is a type III phosphodiesterase inhibitor registered for the treatment of intermittent claudication. Several clinical trials showed that cilostazol increased the MWD and PFWD as compared to placebo [123, 124]. A systematic review comparing cilostazol with naftidrofuryl and pentoxifylline revealed that cilostazol was slightly less efficient than naftidrofuryl but more efficient than pentoxifylline [ $1 / 8]$. Due to its 
Table I I. Drugs with confirmed or potential efficacy in treating intermittent claudication

Drug Characteristics and evidence of benefits

Drugs with confirmed clinical efficacy in treating intermittent claudication, recommended by international claudication $[1,2]$

Cilostazol

(dosing: $100 \mathrm{mg} \mathrm{BID)}$

Naftidrofuryl (dosing: $200 \mathrm{mg}$ TID)

Type III phosphodiesterase inhibitor which increases the volume of cyclic AMP, thus inhibiting the contraction of smooth muscles and platelet aggregation. It reduces the proliferation of smooth muscles, which might play a role for patients undergoing angioplasty, and stimulates angiogenesis. Cilostazol also affects the serum levels of lipids, reducing the triglyceride levels and increasing the HDL-C

It is registered by the FDA for treatment of intermittent claudication and improves MWD and PFWD compared to placebo. It is also more efficient than pentoxifylline [1 I8, 123, 124], but its effect may vary $[118,133]$

Frequent side effects include headache, diarrhoea and other gastrointestinal disorders. Due to its mechanism of action, cilostazol can reduce arterial blood pressure and induce arrhythmia. In randomized clinical trials, cilostazol reduced the incidence of restenosis but increased the incidence of hemorrhagic complications in patients who had undergone intravascular treatment [125] Main contraindications include: congestive heart failure, hemorrhagic stroke/unstable angina/ /heart attack/coronary intervention in the previous 6 months, history of significant ventricular arrhythmia, simultaneous use of $\geq 2$ other anticoagulants (antiplatelets or antithrombotics), sever renal impairment $(\mathrm{CrCl} \leq 25 \mathrm{~mL} / \mathrm{min})$

For patients who are simultaneously taking strong CYP3A4 inhibitors (e.g. certain macrolide antibiotics, azole antifungal agents, HIV protease inhibitors), or CYP2CI9 inhibitors (e.g. omeprazole), it is recommended to reduce the dose by half (to $50 \mathrm{mg} \mathrm{BID)}$

Serotonin-2 receptor antagonist which reduces the aggregation of red blood cells and platelets Not registered by FDA; available only in Europe, but currently not available in Poland Systematic review and meta-analysis revealed that it increased MWD and PFWD [134]. In the systematic review, naftidrofuryl showed slightly higher efficacy than cilostazol [1 18] Side effects: mainly gastrointestinal, such as nausea, vomiting, diarrhoea, flatulence, abdominal discomfort. Causes less adverse events than cilostazol

Statins

Registered for use in reducing cardiovascular risk, with the restriction that they are not registered for the treatment of intermittent claudication. The statins' effect on claudication is unknown; they might impact vascular tension or stimulate angiogenesis Side effects: headache, gastrointestinal symptoms (abdominal pain, constipation, flatulence, diarrhoea), muscular pain or myositis, increased liver enzyme activity, rarely cholestatic hepatitis, rhabdomyolysis

A number of meta-analyses have shown that statins significantly improve the PFWD and maximum walking distance (MWD) [3।, I I ] ]. In the randomized CLEVER trial, conservative treatment, including the use of statins, did not significantly improve the walking efficiency or reduce the symptoms in patients with intermittent claudication, as compared to supervised exercise training or stenting [135]

\section{Drugs with potential, but insufficiently confirmed efficacy in treating intermittent claudication}

Pentoxifylline
A methylxanthine derivative, improving oxygenation by increasing the deformation of red blood cells. Pentoxifylline can inhibit platelet aggregation and affect blood coagulation, especially when combined with anticoagulants

It is registered by the FDA for treatment of intermittent claudication. Some studies have shown pentoxifylline to increase PFWD and MWD compared to placebo [136], but a systematic review revealed vastly discrepant results in terms of increasing the walking distance [137]. Its clinical application is thus limited due to the difficulty in identifying patients who would benefit from treatment [137]

The ESC and ACC/AHA guidelines [I, 2] do not recommend using pentoxifylline, while the 2015 guidelines of the Society of Vascular Surgery [3] recommend using pentoxifylline if cilostazol is not tolerated or contraindicated. Given the unavailability of naftidrofuryl in Poland, it seems that pentoxifylline may be sometimes considered as an alternative drug for improving the walking performance if cilostazol cannot be used and other methods (quitting smoking, exercise therapy, statins, revascularization) fail to improve the patient's condition or cannot be used 
Table I I (cd). Drugs with confirmed or potential efficacy in treating intermittent claudication

\begin{tabular}{|c|c|}
\hline Lek & Charakterystyka i dowody korzyści \\
\hline \multicolumn{2}{|c|}{ Drugs with potential, but insufficiently confirmed efficacy in treating intermittent claudication } \\
\hline Antiplatelet drugs & $\begin{array}{l}\text { A systematic review revealed that antiplatelet therapy significantly increased PFWD compared } \\
\text { to placebo [I38], but the improvement of the walking distance was achieved mainly for older } \\
\text { antiplatelet drugs, such as ticlopidine, while no evidence of the beneficial effect on LEAD was } \\
\text { achieved for acetylsalicylic acid or clopidogrel. In one small trial, the combination of acetylsalicylic } \\
\text { acid and dipyridamole increased PFWD and resting blood flow in the limbs of patients suffering } \\
\text { from intermittent claudication [139] }\end{array}$ \\
\hline $\begin{array}{l}\text { L-carnitine and propionyl- } \\
\text { L-carnitine }\end{array}$ & $\begin{array}{l}\text { Improve energy metabolism in ischemic muscles. Both propionyl-L-carnitine and L-carnitine were } \\
\text { studied in clinical trials, showing a slight increase of PFWD and MWD compared to placebo, but } \\
\text { finding no benefits compared to walking training [140-144] }\end{array}$ \\
\hline L-arginine & $\begin{array}{l}\text { The drug has an indirect vasodilatory effect on the smooth muscles of the vessels. Administered } \\
\text { intravenously, L-arginine increased MWD compared to placebo, however, no improvement was } \\
\text { found in a 6-month study with an oral preparation }[145,146]\end{array}$ \\
\hline $\begin{array}{l}\text { Prostanoids (prostaglan- } \\
\text { dins EI and I2) }\end{array}$ & $\begin{array}{l}\text { Prostanoids have a vasodilatory and antiplatelet effect. Prostaglandin EI increased MWD } \\
\text { compared to placebo }[119,147] ; \text { however, in the trials with beraprost (prostacyclin analogue), } \\
\text { inconsistent results were obtained }[148,149]\end{array}$ \\
\hline $\begin{array}{l}\text { Angiotensin-converting- } \\
\text { enzyme inhibitors (ACEI) }\end{array}$ & $\begin{array}{l}\text { May be preferable for treatment of patients with PAD and arterial hypertension due to their } \\
\text { vasodilatory effect and improvement of endothelial function, as well as the confirmed reduction } \\
\text { of cardiovascular risk in patients with PAD through the renin-angiotensin system inhibitors } \\
\text { A randomized clinical trial showed that ACEI increased the walking distance in patients with } \\
\text { intermittent claudication [67] } \\
\text { The results of trials using ACE inhibitors are controversial, since of the six trials with ACE } \\
\text { inhibitors compared to placebo which was included in the meta-analysis in } 2013 \text { [68], } \\
\text { an improvement in the walking distance was observed in three trials with ramipril, two of which } \\
\text { were subsequently retracted due to unreliable data [69], while three trials with other ACE } \\
\text { inhibitors (captopril, cilazapril, perindopril), no benefits were achieved. In the new meta-analysis, } \\
\text { which included only the four trials remaining after the two studies on ramipril had been retracted, } \\
\text { no improvement of the walking distance was found [70] }\end{array}$ \\
\hline Verapamil & $\begin{array}{l}\text { Calcium antagonist which does not belong to dihydropyridine derivatives. A randomized clinical } \\
\text { trial showed that verapamil extended the walking distance in patients with LEAD [66] }\end{array}$ \\
\hline $\begin{array}{l}\text { Maidenhair tree } \\
\text { (Gingko biloba) }\end{array}$ & $\begin{array}{l}\text { The mechanism of action of the maidenhair tree has not been fully explaining, but is likely an } \\
\text { antioxidant and anticoagulant, inhibiting vascular injuries. A meta-analysis of II clinical trials only } \\
\text { showed a trend towards the improvement of MWD [150] }\end{array}$ \\
\hline Sulodexide & $\begin{array}{l}\text { A substance with a broad spectrum of effects (anticoagulant, profibrinolytic, anti-inflammatory, } \\
\text { inhibiting fibrosis and protecting vascular endothelial cells) } \\
\text { The major international guidelines [I-3] do not list sulodexide among the drugs which are } \\
\text { potentially useful in treating intermittent claudication, but in a randomized, double-blinded, placebo- } \\
\text { controlled SUAVIS clinical trial, an improvement of MWD and PFWD was shown at } 6 \text { months of } \\
\text { treatment. The results of treatment in patients with and without diabetes were similar [I20] }\end{array}$ \\
\hline Padma 28 & $\begin{array}{l}\text { Padma } 28 \text { is a traditional Tibetan medicine containing } 22 \text { herbal ingredients. The review of trials } \\
\text { in the Cochrane database yielded some data indicating an improvement of the walking distance, } \\
\text { at least in short-term trials [ } 15 \mathrm{I}] \text {. Long-term treatment effects are unknown. The available data } \\
\text { have limited methodological value and the clinical significance of the observed walking } \\
\text { performance improvement is questionable }\end{array}$ \\
\hline
\end{tabular}

All abbreviations in the text

antiplatelet action which increases the bleeding risk, care must be taken when combining cilostazol with other antiplatelets and anticoagulants, and also when using the drug in patients with other bleeding risk factors (e.g. active ulcer or improperly controlled arterial hypertension). In randomized clinical trials, cilostazol reduced the incidence of restenosis but increased the incidence of hemorrhagic complications in patients who had undergone intravascular treatment [125]. Frequent side effects include headache, diarrhoea and other gastrointestinal disorders. Due to its mechanism of action, cilostazol can reduce arterial blood pressure and induce arrhythmia. Main contraindications include congestive heart failure, history of significant ventricular 
Table 12. Recommendations on drugs improving the walking distance

\begin{tabular}{|c|c|c|}
\hline Recommendation & $\begin{array}{l}\text { Class of } \\
\text { recommendation }\end{array}$ & $\begin{array}{l}\text { Level (quality) } \\
\text { of evidence }\end{array}$ \\
\hline $\begin{array}{l}\text { Cilostazol is recommended as a first-line symptomatic treatment drug to increase the } \\
\text { pain-free walking distance in patients with LEAD and intermittent claudication provided } \\
\text { that there are no contraindications for use }\end{array}$ & I & A \\
\hline $\begin{array}{l}\text { Pentoxifylline may be considered as an alternative drug to increase the walking distance } \\
\text { if cilostazol cannot be used The clinical efficacy of pentoxifylline in treating intermittent } \\
\text { claudication has not been clearly confirmed and exhibit inter-individual variability }\end{array}$ & Ilb & B \\
\hline $\begin{array}{l}\text { Sulodexide may be considered in the treatment of intermittent claudication in patients } \\
\text { with LEAD }\end{array}$ & Ilb & B \\
\hline $\begin{array}{l}\text { The efficacy of other agents, such as L-arginine, L-carnitine/propionyl-L-carnitine, } \\
\text { maidenhair tree (Gingko biloba) and prostanoids have not been unequivocally confirmed }\end{array}$ & \multicolumn{2}{|c|}{ GPS } \\
\hline $\begin{array}{l}\text { Chelation therapy is inefficient in treating intermittent claudication and may have harmful } \\
\text { side effects }\end{array}$ & III & B \\
\hline
\end{tabular}

LEAD: lower extremity artery disease

\begin{tabular}{|c|c|}
\hline Asymptomatic PAD & Symptomatic PAD \\
\hline $\begin{array}{l}\text { No symptoms + no history of peripheral } \\
\text { revascularization }+\mathrm{ABI}<0,90\end{array}$ & 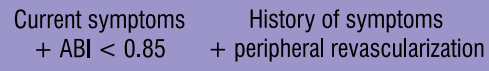 \\
\hline $\begin{array}{l}\text { Therapies for MACE reduction } \\
\text { - Lifestyle modificat ion } \\
\text { - Tobacco cessation therapies } \\
\text { - Statin therapy } \\
\text { - Blood pressure control (ACEi or ARB preferred) } \\
\text { - Antiplatelet monotherapy may be beneficial } \\
\text { in selected patients }\end{array}$ & $\begin{array}{l}\text { Therapies for MACE Reduction } \\
\text { - Lifestyle Modification } \\
\text { - Tobacco Cessation Therapies } \\
\text { - Statin therapy } \\
\text { - Blood Pressure control (ACEi or ARB preferred) } \\
\text { - ASA or Thienopyridine } \\
\text { - PAR-1 Antagonist } \\
\text { Therapies for Limb Vascular Event Risk Reduction } \\
\text { - Statin therapy may be beneficial } \\
\text { - PAR-1 Antagonist for selected patients } \\
\text { Therapies for symptom improvement } \\
\text { - Exercise } \\
\text { - Cilostazol } \\
\text { - Revatin therapy may be beneficial }\end{array}$ \\
\hline
\end{tabular}

Figure 4. Key information in the comprehensive approach to the treatment of patients with atherosclerotic lower extremity artery disease (modified from [152])

arrhythmia and simultaneous use of $\geq 2$ other anticoagulants (antiplatelets or antithrombotics).

The treatment methods, for which no clinical benefits in terms of improving claudication and which are not recommended, include antithrombotic agents (warfarin and low molecular weight heparin) [126], hormone replacement therapy [127, 128], garlic [129], vitamin E supplementation [130] and chelation therapy [131, 132].

Drugs with confirmed or potential clinical efficacy in treating intermittent claudication are listed in Table I I . The recommendations on the use of drugs improving the walking distance are listed in Tables II, 12. 


\section{Summary}

The objective of the comprehensive treatment of LEAD is to reduce the risk of cardiovascular events and limb-related incidents and to improve the LEAD symptoms. The main treatment methods for patients with LEAD are provided in Figure 4. Following the review of the available evidence from scientific studies and formulation of the therapeutic recommendations, the Workgroup proposes the following 10 principles of conservative treatment of patients with LEAD:

I. Quitting smoking and using other non-pharmacological methods to reduce cardiovascular risk (healthy diet, exercise).

2. Administering statins to patients with LEAD in order to achieve the target LDL-C level $<1.8 \mathrm{mmol} / \mathrm{L}$ (70 $\mathrm{mg} / \mathrm{dL}$ ), or reduce it by $\geq 50 \%$, if the initial LDL-C level is $1.8-3.5 \mathrm{mmol} / \mathrm{L}(70-135 \mathrm{mg} / \mathrm{dL})$.

3. Treating the concomitant arterial hypertension and diabetes.

4. Anticoagulation therapy for patients with symptomatic LEAD or who have undergone revascularization.

5. In most patients, the basic treatment method is a single antiplatelet drug (ASA or clopidogrel, whereby clopidogrel may be preferable).

6. A promising new treatment strategy, providing an alternative to single antiplatelet therapy, is the combined anticoagulation therapy with ASA and a small dose of rivaroxaban.

7. Dual antiplatelet therapy is applied mainly in the initial period ( $\geq$ I month) after intravascular revascularization, and in patients with an indication for dual antiplatelet therapy arising from the concomitant coronary artery disease.

8. Oral anticoagulation is applied mainly in patients with separate indications for such therapy (such as atrial fibrillation with stroke risk factors), usually as monotherapy, i.e. without the antiplatelet therapy, or in combination with a single antiplatelet drug, provided that there are other indications (e.g. int he first month following the implantation of a stent in peripheral vessels).

9. The basic method of symptomatic treatment of intermittent claudication is exercise therapy, i.e. walking training.

10. Cilostazol is the drug of choice to supplement the treatment increasing the claudication distance.

\section{Conflict of interest}

None.

\section{References:}

I. Aboyans V, Björck M, Brodmann M, et al. ESC Scientific Document Group , ESC Scientific Document Group . 2017 ESC Gu- idelines on the Diagnosis and Treatment of Peripheral Arterial Diseases, in collaboration with the European Society for Vascular Surgery (ESVS)]. Kardiol Pol. 2017; 75(I I): 1065-I 160, doi: 10.5603/KP.2017.0216, indexed in Pubmed: 29589371.

2. Gerhard-Herman MD, Gornik HL, Barrett C, et al. 2016 AHA ACC Guideline on the Management of Patients With Lower Extremity Peripheral Artery Disease: A Report of the American College of Cardiology/American Heart Association Task Force on Clinical Practice Guidelines. Circulation. 2017; 135(I2): e726-e779, doi: 10.1 16I/CIR.000000000000047I, indexed in Pubmed: 27840333.

3. Conte MS, Pomposelli FB, Clair DG, et al. Society for Vascular Surgery Lower Extremity Guidelines Writing Group, Society for Vascular Surgery. Society for Vascular Surgery practice guidelines for atherosclerotic occlusive disease of the lower extremities: management of asymptomatic disease and claudication. J Vasc Surg. 2015; 6I (3 Suppl): 2S-4IS, doi: 10.1016/j. jvs.2014.12.009, indexed in Pubmed: 25638515.

4. Norgren L, Hiatt WR, Dormandy JA, et al. TASC II Working Group. Inter-Society Consensus for the Management of Peripheral Arterial Disease (TASC II). Eur J Vasc Endovasc Surg. 2007; 33 Suppl I: SI-75, doi: 10.1016/j.ejvs.2006.09.024, indexed in Pubmed: $17 \mid 40820$.

5. Dormandy JA, Rutherford RB. Management of peripheral arterial disease (PAD). TASC Working Group. TransAtlantic Inter-Society Consensus (TASC). J Vasc Surg. 2000; 3 I (I Pt 2): SI-S296, indexed in Pubmed: 10666287.

6. Grøndal N, Søgaard R, Lindholt JS. Baseline prevalence of abdominal aortic aneurysm, peripheral arterial disease and hypertension in men aged 65-74 years from a population screening study (VIVA trial). Br J Surg. 2015; 102(8): 902-906, doi: 10.1002/bjs.9825, indexed in Pubmed: 25923784.

7. Sigvant B, Wiberg-Hedman K, Bergqvist D, et al. A population-based study of peripheral arterial disease prevalence with special focus on critical limb ischemia and sex differences. J Vasc Surg. 2007; 45(6): II85-I191, doi: 10.1016/j.jvs.2007.02.004, indexed in Pubmed: 17543683.

8. Kannel WB. Risk factors for atherosclerotic cardiovascular outcomes in different arterial territories. J Cardiovasc Risk. 1994; I (4): 333-339, indexed in Pubmed: 762I 317.

9. Wilterdink JL, Easton JD. Vascular event rates in patients with atherosclerotic cerebrovascular disease. Arch Neurol. 1992; 49(8): 857-863, indexed in Pubmed: 1524519.

10. Criqui MH, Langer RD, Fronek A, et al. Mortality over a period of 10 years in patients with peripheral arterial disease. N Engl J Med. 1992; 326(6): 38I-386, doi: 10.1056/ NEJMI 99202063260605 , indexed in Pubmed: 1729621.

II. Rykowski H. Choroby naczyń. PZWL, Warszawa 1990.

12. Leng GC, Lee AJ, Fowkes FG, et al. Incidence, natural history and cardiovascular events in symptomatic and asymptomatic peripheral arterial disease in the general population. Int J Epidemiol. 1996; 25(6): I 172-1 181, indexed in Pubmed: 902752।.

13. Newman AB, Shemanski L, Manolio TA, et al. Ankle-arm index as a predictor of cardiovascular disease and mortality in the Cardiovascular Health Study. The Cardiovascular Health Study Group. Arterioscler Thromb Vasc Biol. 1999; 19(3): 538-545, indexed in Pubmed: 10073955. 
14. Aronow WS, Ahmed MI, Ekundayo OJ, et al. A propensity-matched study of the association of peripheral arterial disease with cardiovascular outcomes in community-dwelling older adults. Am J Cardiol. 2009; 103(1): 130-135, doi: 10.1016/j. amjcard.2008.08.037, indexed in Pubmed: 19101243.

15. Ostergren J, Sleight P, Dagenais G, et al. HOPE study investigators. Impact of ramipril in patients with evidence of clinical or subclinical peripheral arterial disease. Eur Heart J. 2004; 25(I): 17-24, indexed in Pubmed: 14683738.

16. Gupta DK, Skali $H$, Claggett $B$, et al. Heart failure risk across the spectrum of ankle-brachial index: the ARIC study (Atherosclerosis Risk In Communities). JACC Heart Fail. 2014; 2(5): 447-454, doi: 10.1016/j.jchf.2014.05.008, indexed in Pubmed: 25194293.

17. Tehan PE, Santos D, Chuter VH. A systematic review of the sensitivity and specificity of the toe-brachial index for detecting peripheral artery disease. Vasc Med. 2016; 2 I (4): 382-389, doi: 10.1 177//358863X16645854, indexed in Pubmed: 27/657/2.

18. Piepoli MF, Hoes AW, Agewall S, et al. Authors/Task Force Members:, Authors/Task Force Members, Additional Contributor: Simone Binno (Italy), Document Reviewers:, ESC Scientific Document Group. 2016 European Guidelines on cardiovascular disease prevention in clinical practice: The Sixth Joint Task Force of the European Society of Cardiology and Other Societies on Cardiovascular Disease Prevention in Clinical Practice (constituted by representatives of 10 societies and by invited experts)Developed with the special contribution of the European Association for Cardiovascular Prevention \& Rehabilitation (EACPR). Eur Heart J. 2016; 37(29): 23I5-238I, doi: 10.1093/eurheartj/ehw106, indexed in Pubmed: 2722259I.

19. JUERGENS J, BARKER N, HINES E. Arteriosclerosis Obliterans: Review of 520 Cases with Special Reference to Pathogenic and Prognostic Factors. Circulation. 1960; 2 I (2): 188-195, doi: 10.1161/01.cir.21.2.188.

20. Gardner AW, Poehlman ET. Exercise rehabilitation programs for the treatment of claudication pain. A meta-analysis. JAMA. 1995; 274(I2): 975-980, indexed in Pubmed: 7674529.

21. Stewart KJ, Hiatt WR, Regensteiner JG, et al. Exercise training for claudication. N Engl J Med. 2002; 347(24): 1941-195I, doi: 10.1056/NEJMra02 I I35, indexed in Pubmed: 12477945.

22. Hageman D, Fokkenrood HJp, Gommans LNm, et al. Supervised exercise therapy versus home-based exercise therapy versus walking advice for intermittent claudication. Cochrane Database Syst Rev. 2018; 4: CD005263, doi: 10.1002/14651858. CD005263.pub4, indexed in Pubmed: 29627967.

23. Hiatt WR, Wolfel EE, Meier RH, et al. Superiority of treadmill walking exercise versus strength training for patients with peripheral arterial disease. Implications for the mechanism of the training response. Circulation. 1994; 90(4): 1866-1874, indexed in Pubmed: 7923674.

24. Lane R, Ellis B, Watson $L$, et al. Exercise for intermittent claudication. Cochrane Database Syst Rev. 2014(7): CD000990, doi: 10.1002//465 I858.CD000990.pub3, indexed in Pubmed: 25037027.
25. Gommans LNM, Fokkenrood HJP, van Dalen HCW, et al. Safety of supervised exercise therapy in patients with intermittent claudication. J Vasc Surg. 2015; 6I(2): 512-518.e2, doi: 10.1016/j.jvs.2014.08.070, indexed in Pubmed: 25441008.

26. Fokkenrood HJP, Bendermacher BLW, Lauret GJ, et al. Supervised exercise therapy versus non-supervised exercise therapy for intermittent claudication. Cochrane Database Syst Rev. 2013(8): CD005263, doi: 10.1002/1465 I858.CD005263.pub3, indexed in Pubmed: 23970372.

27. Kruidenier LM, Nicolaï SP, Rouwet EV, et al. Additional supervised exercise therapy after a percutaneous vascular intervention for peripheral arterial disease: a randomized clinical trial. J Vasc Interv Radiol. 20I I; 22(7): 96I-968, doi: 10.1016/j. jvir.2011.02.017, indexed in Pubmed: 21571547.

28. Bäck $M$, Jivegård L, Johansson $A$, et al. Home-based supervised exercise versus hospital-based supervised exercise or unsupervised walk advice as treatment for intermittent claudication: a systematic review. J Rehabil Med. 2015; 47(9): 80 I-808, doi: 10.2340/16501977-2012, indexed in Pubmed: 26435098.

29. Lauret GJ, Fakhry F, Fokkenrood HJP, et al. Modes of exercise training for intermittent claudication. Cochrane Database Syst Rev. 2014(7): CD009638, doi: 10.1002/I465I858.CD009638. pub2, indexed in Pubmed: 24993079.

30. Al-Jundi W, Madbak K, Beard JD, et al. Systematic review of home-based exercise programmes for individuals with intermittent claudication. Eur J Vasc Endovasc Surg. 2013; 46(6): 690-706, doi: 10. 10 I6/j.ejvs.2013.09.004, indexed in Pubmed: 24076079.

31. Aung PP, Maxwell HG, Jepson RG, et al. Lipid-lowering for peripheral arterial disease of the lower limb. Cochrane Database Syst Rev. 2007(4): CD000123, doi: 10.1002/1465I858. CD000 I23.pub2, indexed in Pubmed: 17943736.

32. Antoniou GA, Fisher RK, Georgiadis GS, et al. Statin therapy in lower limb peripheral arterial disease: Systematic review and meta-analysis. Vascul Pharmacol. 2014; 63(2): 79-87, doi: 10.1016/j.vph.2014.09.001, indexed in Pubmed: 25446I68.

33. Heart Protection Study Collaborative Group. Randomized trial of the effects of cholesterol-lowering with simvastatin on peripheral vascular and other major vascular outcomes in 20,536 people with peripheral arterial disease and other high-risk conditions. J Vasc Surg. 2007; 45(4): 645-654; discussion 653, doi: 10.1016/j.jvs.2006.12.054, indexed in Pubmed: 17398372.

34. Kumbhani DJ, Steg PhG, Cannon CP, et al. REACH Registry Investigators. Statin therapy and long-term adverse limb outcomes in patients with peripheral artery disease: insights from the REACH registry. Eur Heart J. 2014; 35(4I): 2864-2872, doi: 10. 1093/eurhearti/ehu080, indexed in Pubmed: 24585266.

35. Westin GG, Armstrong EJ, Bang H, et al. Association between statin medications and mortality, major adverse cardiovascular event, and amputation-free survival in patients with critical limb ischemia. J Am Coll Cardiol. 2014; 63(7): 682-690, doi: 10.1016/j.jacc.2013.09.073, indexed in Pubmed: 243 I591।.

36. Murphy SA, Cannon CP, Blazing MA, et al. Reduction in Total Cardiovascular Events With Ezetimibe/Simvastatin Post-Acute Coronary Syndrome: The IMPROVE-IT Trial. J Am Coll Cardiol. 
2016; 67(4): 353-36I, doi: 10.1016/j.jacc.2015.10.077, indexed in Pubmed: 26821621.

37. Meade T, Zuhrie R, Cook C, et al. Bezafibrate in men with lower extremity arterial disease: randomised controlled trial. BMJ. 2002; 325(7373): I 139, doi: 10.1 I36/bmj.325.7373.1 I39, indexed in Pubmed: 12433762.

38. Murphy SA, Cannon CP, Blazing MA, et al. Reduction in Total Cardiovascular Events With Ezetimibe/Simvastatin Post-Acute Coronary Syndrome: The IMPROVE-IT Trial. J Am Coll Cardiol. 2016; 67(4): 353-36I, doi: 10.1016/j.jacc.2015.10.077, indexed in Pubmed: 26821621.

39. Bonaca MP, Nault P, Giugliano RP, et al. Low-Density Lipoprotein Cholesterol Lowering With Evolocumab and Outcomes in Patients With Peripheral Artery Disease: Insights From the FOURIER Trial (Further Cardiovascular Outcomes Research With PCSK9 Inhibition in Subjects With Elevated Risk). Circulation. 2018; 137(4): 338-350, doi: 10.1161/CIRCULATIONAHA. I 17.032235, indexed in Pubmed: 29/33605.

40. Diabetology C. 2018 Guidelines on the management of diabetic patients. A position of Diabetes Poland. Clinical Diabetology. 2018; 7(1): I-90, doi: 10.5603/dk.2018.000।.

4I. Singh S, Armstrong EJ, Sherif W, et al. Association of elevated fasting glucose with lower patency and increased major adverse limb events among patients with diabetes undergoing infrapopliteal balloon angioplasty. Vasc Med. 2014; 19(4): 307314, doi: 10.1 177/1358863X14538330, indexed in Pubmed: 24939930.

42. Takahara $\mathrm{M}$, Kaneto $\mathrm{H}$, lida $\mathrm{O}$, et al. The influence of glycemic control on the prognosis of Japanese patients undergoing percutaneous transluminal angioplasty for critical limb ischemia. Diabetes Care. 2010; 33(I2): 2538-2542, doi: 10.2337/dc I00939, indexed in Pubmed: 20843974.

43. Wanner C, Lachin JM, Inzucchi SE, et al. EMPA-REG OUTCOME Investigators, EMPA-REG OUTCOME ${ }^{\circ}$ trial investigators, EMPA-REG OUTCOME Investigators. Empagliflozin, Cardiovascular Outcomes, and Mortality in Type 2 Diabetes. N Engl J Med. 2015; 373(22): 2117-2128, doi: 10.1056/NEJMoal504720, indexed in Pubmed: 26378978.

44. Verma S, Mazer CD, Al-Omran M, et al. Cardiovascular Outcomes and Safety of Empagliflozin in Patients With Type 2 Diabetes Mellitus and Peripheral Artery Disease: A Subanalysis of EMPA-REG OUTCOME. Circulation. 2018; 137(4): 405-407, doi: 10.1161/CIRCULATIONAHA.117.032031, indexed in Pubmed: 29133602.

45. Mathers C, Stevens G, Mascarenhas M. Global health risks: mortality and burden of disease attributable to selected major risks. World Health Organization. Geneva, Switzerland 2009 . http://www.who.int/healthinfo/global_burden_disease/global_health_risks/en/index.html.

46. GBD 2015 Risk Factors Collaborators. Global, regional, and national comparative risk assessment of 79 behavioural, environmental and occupational, and metabolic risks or clusters of risks, 1990-2015: a systematic analysis for the Global Burden of Disease Study 2015. Lancet. 2016;388:1659-1724.
47. Zdrojewski $Ł$, Zdrojewski T, Rutkowski M, et al. Prevalence and control of cardiovascular risk factors in Poland. Assumptions and objectives of the NATPOL 201 I Survey. Kardiol Pol. 20I3; 7I(4): 38I-392, doi: 10.5603/KP.20।3.0066, indexed in Pubmed: 23788344.

48. Meijer WT, Grobbee DE, Hunink MG, et al. Peripheral arterial disease in the elderly: The Rotterdam Study. Arterioscler Thromb Vasc Biol. 1998; 18(2): 185-192, indexed in Pubmed: 9484982.

49. Selvin E, Erlinger TP. Prevalence of and risk factors for peripheral arterial disease in the United States: results from the National Health and Nutrition Examination Survey, 1999 2000. Circulation. 2004; 110(6): 738-743, doi: 10.1161/01. CIR.0000I379|3.26087.F0, indexed in Pubmed: 15262830.

50. Murabito JM, D'Agostino RB, Silbershatz H, et al. Intermittent claudication. A risk profile from The Framingham Heart Study. Circulation. 1997; 96(I): 44-49, indexed in Pubmed: 9236415.

51. Ostchega Y, Paulose-Ram R, Dillon CF, et al. Prevalence of peripheral arterial disease and risk factors in persons aged 60 and older: data from the National Health and Nutrition Examination Survey 1999-2004. J Am Geriatr Soc. 2007; 55(4): 583-589, doi: 10.1 III/j.1532-5415.2007.01।23.x, indexed in Pubmed: 17397438.

52. Emdin CA, Anderson SG, Callender T, et al. Usual blood pressure, peripheral arterial disease, and vascular risk: cohort study of 4.2 million adults. BMJ. 2015; 35I: h4865, doi: 10.1 I36/bmj. h4865, indexed in Pubmed: 26419648.

53. Palumbo PJ, O'Fallon WM, Osmundson PJ, et al. Progression of peripheral occlusive arterial disease in diabetes mellitus. What factors are predictive? Arch Intern Med. 1991; 15I(4): 7|7-72I, indexed in Pubmed: 2012454.

54. Ostergren J, Sleight P, Dagenais G, et al. HOPE study investigators. Impact of ramipril in patients with evidence of clinical or subclinical peripheral arterial disease. Eur Heart J. 2004; 25(I): 17-24, indexed in Pubmed: 14683738.

55. Whelton PK, Carey RM, Aronow WS, et al. 2017 ACC/AHA/ AAPA/ABC/ACPM/AGS/APhA/ASH/ASPC/NMA/PCNA Guideline for the Prevention, Detection, Evaluation, and Management of High Blood Pressure in Adults: Executive Summary: A Report of the American College of Cardiology/ American Heart Association Task Force on Clinical Practice Guidelines. Hypertension. 2018; 7|(6): |269-1324, doi: 10.1161/ HYP.0000000000000066, indexed in Pubmed: 29133354.

56. Bavry AA, Anderson RD, Gong Y, et al. Outcomes Among hypertensive patients with concomitant peripheral and coronary artery disease: findings from the INternational VErapamil-SR/Trandolapril STudy. Hypertension. 2010; 55(I): 48-53, doi: 10.1161/HYPERTENSIONAHA.109.142240, indexed in Pubmed: 19996066.

57. Wright JT, Williamson JD, Whelton PK, et al. A Randomized Trial of Intensive versus Standard Blood-Pressure Control. New England Journal of Medicine. 2015; 373(22): 2103-2116, doi: 10.1056/nejmoal5II939. 
58. Cushman WC, Whelton PK, Fine LJ, et al. SPRINT Study Research Group. SPRINT Trial Results: Latest News in Hypertension Management. Hypertension. 2016; 67(2): 263-265, doi: 10.1 161/HYPERTENSIONAHA. I 15.06722, indexed in Pubmed: 26553234.

59. Yusuf S, Sleight P, Pogue J, et al. Heart Outcomes Prevention Evaluation Study Investigators. Effects of an angiotensin-converting-enzyme inhibitor, ramipril, on cardiovascular events in high-risk patients. N Engl J Med. 2000; 342(3): 145-153, doi: 10.1056/ NEJM20000I 20342030I, indexed in Pubmed: 10639539.

60. Böhm M, Schumacher H, Teo KK, et al. ONTARGET Investigators, ONTARGET Investigators, ONTARGET Investigators, ONTARGET investigators, Ongoing Telmisartan Alone and in Combination With Ramipril Global End Point Trial (ONTARGET)/Telmisartan Randomized Assessment Study in ACEI Intolerant Subjects With Cardiovascular Disease (TRANSCEND) Trial Investigators, OnTARGET/TRANSCEND Investigators, Ongoing Telmisartan Alone and in Combination With Ramipril Global EndPoint Trial (ONTARGET), Telmisartan Randomized Assessment Study in ACE Intolerant Subjects With Cardiovascular Disease (TRANSCEND) Investigators, ONTARGET (ONgoing Telmisartan Alone and in combination with Ramipril Global Endpoint Trial) and TRANSCEND (Telmisartan Randomized Assessment Study in Angiotensin-Converting-Enzyme-Inhibitor Intolerant Subjects with Cardiovascular Disease), ONTARGET and TRANSCEND Investigators, ONTARGET investigators, ONTARGET Investigators. Telmisartan, ramipril, or both in patients at high risk for vascular events. N Engl J Med. 2008; 358(I5): 1547-1559, doi: 10. 1056/NEJMoa0801317, indexed in Pubmed: 18378520.

6I. Armstrong EJ, Chen DC, Singh GD. Angiotensin-converting enzyme inhibitor or angiotensin receptor blocker use is associated with reduced major adverse cardiovascular events among patients with critical limb ischemia. Vasc Med. 2015; 20: 237-244.

62. Aronow WS, Ahn C. Effect of beta blockers on incidence of new coronary events in older persons with prior myocardial infarction and symptomatic peripheral arterial disease. Am J Cardiol. 200 I; 87( I I): 1284-1286, indexed in Pubmed: I 377356.

63. Paravastu SC, Mendonca DA, Da Silva A, et al. Beta blockers for peripheral arterial disease. Eur J Vasc Endovasc Surg. 2009; 38(I): 66-70, doi: 10.1016/j.ejvs.2009.02.019, indexed in Pubmed: 19359199.

64. Soga Y, lida O, Takahara M, et al. Beta-blocker Treatment Does Not Worsen Critical Limb Ischemia in Patients Receiving Endovascular Therapy. J Atheroscler Thromb. 2015; 22(5): 48I-489, doi: 10.555 I/jat.27359, indexed in Pubmed: 25445890.

65. Mirault T, Galloula A, Cambou JP, et al. Impact of betablockers on general and local outcome in patients hospitalized for lower extremity peripheral artery disease: The COPART Registry. Medicine (Baltimore). 2017; 96(5): e5916, doi: 10.1097/ MD. 0000000000005916 , indexed in Pubmed: 28151868.

66. Bagger JP, Helligsoe P, Randsbaek F, et al. Effect of verapamil in intermittent claudication A randomized, double-blind, placebo-con- trolled, cross-over study after individual dose-response assessment. Circulation. 1997; 95(2): 4II-4I4, indexed in Pubmed: 9008458.

67. Shahin Y, Cockcroft JR, Chetter IC. Randomized clinical trial of angiotensin-converting enzyme inhibitor, ramipril, in patients with intermittent claudication. Br J Surg. 2013; 100(9): II54-I 163, doi: 10.1002/bjs.9198, indexed in Pubmed: 23842829.

68. Shahin $\mathrm{Y}$, Barnes $\mathrm{R}$, Barakat $\mathrm{H}$, et al. Meta-analysis of angiotensin converting enzyme inhibitors effect on walking ability and ankle brachial pressure index in patients with intermittent claudication. Atherosclerosis. 2013; 231(2): 283-290, doi: 10.1016/j.atherosclerosis.2013.09.037, indexed in Pubmed: 2426724I.

69. McCarthy M. Ramipril research papers are retracted over faked data. BMJ. 20I5; 35 I: h5035, doi: 10.I I36/bmj.h5035, indexed in Pubmed: 26391363.

70. Vlachopoulos C, Terentes-Printzios D, Aboyans V, et al. Angiotensin converting enzyme inhibitors and walking distance: Have we walked the whole distance? Atherosclerosis. 2016; 252: 199-200, doi: 10.1016/j.atherosclerosis.2016.08.001, indexed in Pubmed: 27543007.

71. Espinola-Klein $\mathrm{C}$, Weisser $\mathrm{G}$, Jagodzinski $\mathrm{A}$, et al. $\beta$-Blockers in patients with intermittent claudication and arterial hypertension: results from the nebivolol or metoprolol in arterial occlusive disease trial. Hypertension. 201 I; 58(2): 148-154, doi: 10.1161/HYPERTENSIONAHA.110.169169, indexed in Pubmed: 21646599.

72. Dziewierz A, Dudek D. Nowe leki przeciwpłytkowe — które, u kogo i jak długo stosować? Kardiologia po Dyplomie. 20।2; II: 17-27.

73. Hussain MA, Al-Omran M, Creager MA, et al. Antithrombotic Therapy for Peripheral Artery Disease: Recent Advances. J Am Coll Cardiol. 2018; 7I(21): 2450-2467, doi: 10.1016/j. jacc.2018.03.483, indexed in Pubmed: 29793635.

74. Fowkes FG, Price JF, Stewart MCW, et al. Aspirin for Asymptomatic Atherosclerosis Trialists. Aspirin for prevention of cardiovascular events in a general population screened for a low ankle brachial index: a randomized controlled trial. JAMA. 2010; 303(9): 841-848, doi: 10.1001/jama.2010.221, indexed in Pubmed: 20197530.

75. Belch J, MacCuish A, Campbell I, et al. Prevention of Progression of Arterial Disease and Diabetes Study Group, Diabetes Registry Group, Royal College of Physicians Edinburgh. The prevention of progression of arterial disease and diabetes (POPADAD) trial: factorial randomised placebo controlled trial of aspirin and antioxidants in patients with diabetes and asymptomatic peripheral arterial disease. BMJ. 2008; 337: al840, doi: 10.1136/bmj.al840, indexed in Pubmed: 18927173.

76. Antithrombotic Trialists' Collaboration. Collaborative meta-analysis of randomised trials of antiplatelet therapy for prevention of death, myocardial infarction, and stroke in high risk patients. BMJ. 2002; 324(7329): 7I-86, doi: 10.1136/ bmj.324.7329.7I, indexed in Pubmed: I 178645।.

77. Catalano M, Born G, Peto R. Critical Leg Ischaemia Prevention Study (CLIPS) Group. Prevention of serious vascular events by aspirin amongst patients with peripheral arterial disease: 
randomized, double-blind trial. J Intern Med. 2007; 26I(3): 276-284, doi: 10.1 III/j.1365-2796.2006.01763.x, indexed in Pubmed: 17305650.

78. Berger JS, Krantz MJ, Kittelson JM, et al. Aspirin for the prevention of cardiovascular events in patients with peripheral artery disease: a meta-analysis of randomized trials. JAMA. 2009; 30I(18): 1909-1919, doi: 10.1001/jama.2009.623, indexed in Pubmed: 19436018.

79. CAPRIE Steering Committee. A randomised, blinded, trial of clopidogrel versus aspirin in patients at risk of ischaemic events (CAPRIE). CAPRIE Steering Committee. Lancet. 1996; 348(9038): 1329-1339, indexed in Pubmed: 89/8275.

80. Katsanos K, Spiliopoulos S, Saha P, et al. Comparative Efficacy and Safety of Different Antiplatelet Agents for Prevention of Major Cardiovascular Events and Leg Amputations in Patients with Peripheral Arterial Disease: A Systematic Review and Network Meta-Analysis. PLoS One. 2015; 10(8): e0135692, doi: 10.1371/journal.pone.0135692, indexed in Pubmed: 26274912.

81. Hiatt WR, Fowkes FG, Heizer G, et al. EUCLID Trial Steering Committee and Investigators. Ticagrelor versus Clopidogrel in Symptomatic Peripheral Artery Disease. N Engl J Med. 2017; 376(I): 32-40, doi: 10.1056/NEJMoa 16/1688, indexed in Pubmed: 27959717.

82. Schmit K, Dolor RJ, Jones WS, et al. Comparative effectiveness review of antiplatelet agents in peripheral artery disease. J Am Heart Assoc. 2014; 3(6): e001330, doi: 10.1161/ JAHA. I13.001330, indexed in Pubmed: 25477329.

83. Cacoub PP, Bhatt DL, Steg PG, et al. CHARISMA Investigators. Patients with peripheral arterial disease in the CHARISMA trial. Eur Heart J. 2009; 30(2): 192-20I, doi: 10.1093/eurheartj/ ehn534, indexed in Pubmed: 19136484.

84. Jones WS, Tricoci P, Huang Z, et al. Vorapaxar in patients with peripheral artery disease and acute coronary syndrome: insights from Thrombin Receptor Antagonist for Clinical Event Reduction in Acute Coronary Syndrome (TRACER). Am Heart J. 2014; I68(4): 588-596, doi: 10.1016/j.ahj.2014.06.017, indexed in Pubmed: 25262270.

85. Bonaca MP, Scirica BM, Creager MA, et al. Vorapaxar in patients with peripheral artery disease: results from TRA2 \{degrees\} P-TIMI 50. Circulation. 2013; I27(14): 1522-9, I529el, doi: 10.1161/CIRCULATIONAHA.1 12.000679, indexed in Pubmed: 23501976.

86. Bonaca MP, Gutierrez JA, Creager MA, et al. Acute Limb Ischemia and Outcomes With Vorapaxar in Patients With Peripheral Artery Disease: Results From the Trial to Assess the Effects of Vorapaxar in Preventing Heart Attack and Stroke in Patients With Atherosclerosis-Thrombolysis in Myocardial Infarction 50 (TRA2 ${ }^{\circ}$ P-TIMI 50). Circulation. 2016; 133(10): 997-1005, doi: 10.1161/CIRCULATIONAHA.115.019355, indexed in Pubmed: 26826179.

87. Valgimigli M, Campo G, Monti M, et al. Prolonging Dual Antiplatelet Treatment After Grading Stent-Induced Intimal Hyper- plasia Study (PRODIGY) Investigators. Short- versus long-term duration of dual-antiplatelet therapy after coronary stenting: a randomized multicenter trial. Circulation. 2012; 125(16): 2015-2026, doi: 10.1161/CIRCULATIONAHA.111.07I589, indexed in Pubmed: 22438530.

88. Franzone A, Piccolo R, Gargiulo G, et al. Prolonged vs Short Duration of Dual Antiplatelet Therapy After Percutaneous Coronary Intervention in Patients With or Without Peripheral Arterial Disease: A Subgroup Analysis of the PRODIGY Randomized Clinical Trial. JAMA Cardiol. 2016; I(7): 795-803, doi: 10.1001/jamacardio.2016.28II, indexed in Pubmed: 27572001.

89. Magnuson EA, Bonaca MP, Bhatt DL, et al. PEGASUS-TIMI 54 Trial Investigators, PEGASUS-TIMI 54 Steering Committee and Investigators. Long-term use of ticagrelor in patients with prior myocardial infarction. N Engl J Med. 2015; 372(19): |79|-1800, doi: 10.1056/NEJMoa 1500857, indexed in Pubmed: 25773268.

90. Bonaca MP, Bhatt DL, Storey RF, et al. Ticagrelor for Prevention of Ischemic Events After Myocardial Infarction in $\mathrm{Pa}$ tients With Peripheral Artery Disease. J Am Coll Cardiol. 2016; 67(23): 2719-2728, doi: 10.1016/j.jacc.2016.03.524, indexed in Pubmed: 27046162.

91. Udell JA, Bonaca MP, Collet JP, et al. Long-term dual antiplatelet therapy for secondary prevention of cardiovascular events in the subgroup of patients with previous myocardial infarction: a collaborative meta-analysis of randomized trials. Eur Heart J. 2016; 37(4): 390-399, doi: 10.1093/eurheartj/ehv443, indexed in Pubmed: 26324537.

92. Valgimigli M, Bueno H, Byrne RA, et al. ESC Scientific Document Group , ESC Committee for Practice Guidelines (CPG), ESC National Cardiac Societies . 2017 ESC focused update on dual antiplatelet therapy in coronary artery disease developed in collaboration with EACTS: The Task Force for dual antiplatelet therapy in coronary artery disease of the European Society of Cardiology (ESC) and of the European Association for Cardio-Thoracic Surgery (EACTS). Eur Heart J. 2018; 39(3): 213-260, doi: 10.1093/eurheartj/ehx419, indexed in Pubmed: 28886622.

93. Anand S, Yusuf S, Xie C, et al. Warfarin Antiplatelet Vascular Evaluation Trial Investigators. Oral anticoagulant and antiplatelet therapy and peripheral arterial disease. N Engl J Med. 2007; 357: 217-227, indexed in Pubmed: I I 383324.

94. Mega JL, Braunwald E, Wiviott SD, et al. ATLAS ACS 2-TIMI 5 I Investigators. Rivaroxaban in patients with a recent acute coronary syndrome. N Engl J Med. 2012; 366(I): 9-19, doi: 10.1056/NEJMoa I I 2277, indexed in Pubmed: 22077/ 92.

95. Eikelboom JW, Connolly SJ, Bosch J. Rivaroxaban with or without aspirin in stable cardiovascular disease. N Engl J Med. 2017; 377: 1319-1330.

96. Anand SS, Bosch J, Eikelboom JW. Rivaroxaban with or without aspirin in patients with stable peripheral or carotid artery disease: an international, randomised, double-blind, placebo-controlled trial. Lancet . 2018; 391: 219-229. 
97. Anand SS, Caron F, Eikelboom JW, et al. Major Adverse Limb Events and Mortality in Patients With Peripheral Artery Disease: The COMPASS Trial. J Am Coll Cardiol. 2018; 71 (20): 2306-2315, doi: 10.1016/j.jacc.2018.03.008, indexed in Pubmed: 29540326.

98. Bonaca MP, Creager MA. Antithrombotic Therapy and Major Adverse Limb Events in Peripheral Artery Disease: A Step Forward. J Am Coll Cardiol. 2018; 7I(20): 2316-2318, doi: 10.1016/j.jacc.2018.04.00I, indexed in Pubmed: 29773159.

99. Bedenis R, Lethaby A, Maxwell H, et al. Antiplatelet agents for preventing thrombosis after peripheral arterial bypass surgery. Cochrane Database Syst Rev. 2015(2): CD000535, doi: 10.1002/I465 I858.CD000535.pub3, indexed in Pubmed: 25695213.

100. Efficacy of oral anticoagulants compared with aspirin after infrainguinal bypass surgery (The Dutch Bypass Oral Anticoagulants or Aspirin Study): a randomised trial. Lancet. 2000; 355(9201): 346-35I, indexed in Pubmed: 10665553.

10I. Johnson WC, Williford WO. Department of Veterans Affairs Cooperative Study \#362. Benefits, morbidity, and mortality associated with long-term administration of oral anticoagulant therapy to patients with peripheral arterial bypass procedures: a prospective randomized study. J Vasc Surg. 2002; 35(3): 4|3-42I, indexed in Pubmed: I 1877686.

102. Jivegård L, Drott C, Gelin J, et al. Effects of three months of low molecular weight heparin (dalteparin) treatment after bypass surgery for lower limb ischemia - a randomised placebo-controlled double blind multicentre trial. Eur J Vasc Endovasc Surg. 2005; 29(2): 190-198, doi: 10.1016/j.ejvs.2004.11.011, indexed in Pubmed: 15649728.

103. Sarac TP, Huber TS, Back MR, et al. Warfarin improves the outcome of infrainguinal vein bypass grafting at high risk for failure. J Vasc Surg. 1998; 28(3): 446-457, indexed in Pubmed: 9737454.

104. Monaco M, Di Tommaso L, Pinna GB, et al. Combination therapy with warfarin plus clopidogrel improves outcomes in femoropopliteal bypass surgery patients. J Vasc Surg. 2012; 56(I): 96-105, doi: 10.1016/j.jvs.2012.01.004, indexed in Pubmed: 22551909.

105. Belch JJF, Dormandy J, Biasi GM, et al. CASPAR Writing Committee. Results of the randomized, placebo-controlled clopidogrel and acetylsalicylic acid in bypass surgery for peripheral arterial disease (CASPAR) trial. J Vasc Surg. 2010; 52(4): 825-33, 833.el, doi: 10.1016/j.jvs.2010.04.027, indexed in Pubmed: 20678878.

106. Dake MD, Ansel GM, Jaff MR, et al. Zilver PTX Investigators. Durable Clinical Effectiveness With Paclitaxel-Eluting Stents in the Femoropopliteal Artery: 5-Year Results of the Zilver PTX Randomized Trial. Circulation. 2016; 133(15): 1472-83; discussion I483, doi: 10.1 16I/CIRCULATIONAHA.I 15.016900, indexed in Pubmed: 26969758.

107. Rosenfield K, Jaff MR, White CJ, et al. LEVANT 2 Investigators. Trial of a Paclitaxel-Coated Balloon for Femoropopliteal Artery Disease. N Engl J Med. 2015; 373(2): 145-153, doi: 10.1056/ NEJMoal 406235, indexed in Pubmed: 26106946.
108. Laird JR, Schneider PA, Tepe G, et al. IN.PACT SFA Trial Investigators. Durability of Treatment Effect Using a Drug-Coated Balloon for Femoropopliteal Lesions: 24-Month Results of IN.PACT SFA. J Am Coll Cardiol. 2015; 66(2I): 2329-2338, doi: 10.1016/j.jacc.2015.09.063, indexed in Pubmed: 26476467.

109. Strobl FF, Brechtel K, Schmehl J, et al. Twelve-month results of a randomized trial comparing mono with dual antiplatelet therapy in endovascularly treated patients with peripheral artery disease. J Endovasc Ther. 2013; 20(5): 699-706, doi: 10.1583/I3-4275MR. I, indexed in Pubmed: 24093324.

I 10. Dagher NN, Modrall JG. Pharmacotherapy before and after revascularization: anticoagulation, antiplatelet agents, and statins. Semin Vasc Surg. 2007; 20(1): 10-14, doi: 10.1053/j. semvascsurg.2007.02.006, indexed in Pubmed: 17386359.

III. Go AS, Hylek EM, Phillips KA, et al. Prevalence of diagnosed atrial fibrillation in adults: national implications for rhythm management and stroke prevention: the AnTicoagulation and Risk Factors in Atrial Fibrillation (ATRIA) Study. JAMA. 200I; 285(18): 2370-2375, indexed in Pubmed: I 343485.

I I2. Griffin WF, Salahuddin T, O'Neal WT, et al. Peripheral arterial disease is associated with an increased risk of atrial fibrillation in the elderly. Europace. 2016; 18(6): 794-798, doi: 10.1093/ europace/euv369, indexed in Pubmed: 26589625.

I I3. Winkel TA, Hoeks SE, Schouten O, et al. Prognosis of atrial fibrillation in patients with symptomatic peripheral arterial disease: data from the REduction of Atherothrombosis for Continued Health (REACH) Registry. Eur J Vasc Endovasc Surg. 2010; 40(I): 9-16, doi: 10.1016/j.ejvs.2010.03.003, indexed in Pubmed: 20385507.

1 14. Wasmer K, Unrath M, Köbe J, et al. Atrial fibrillation is a risk marker for worse in-hospital and long-term outcome in patients with peripheral artery disease. Int J Cardiol. 2015; 199: 223-228, doi: 10.1016/j.ijcard.2015.06.094, indexed in Pubmed: 26209823.

I I5. Kirchhof P, Benussi S, Kotecha D, et al. ESC Scientific Document Group. 2016 ESC Guidelines for the management of atrial fibrillation developed in collaboration with EACTS. Eur Heart J. 2016; 37(38): 2893-2962, doi: 10.1093/eurheartj/ehw210, indexed in Pubmed: 27567408.

1 16. Heidbuchel H, Verhamme P, Alings M, et al. ESC Scientific Document Group. Updated European Heart Rhythm Association Practical Guide on the use of non-vitamin $\mathrm{K}$ antagonist anticoagulants in patients with non-valvular atrial fibrillation. Europace. 2015; 17(10): 1467-1507, doi: 10.1093/europace/ euv309, indexed in Pubmed: 26324838.

1 17. Momsen AH, Jensen MB, Norager CB, et al. Drug therapy for improving walking distance in intermittent claudication: a systematic review and meta-analysis of robust randomised controlled studies. Eur J Vasc Endovasc Surg. 2009; 38(4): 463-474, doi: 10.1016/j.ejvs.2009.06.002, indexed in Pubmed: 19586783.

1 18. Stevens JW, Simpson E, Harnan S, et al. Systematic review of the efficacy of cilostazol, naftidrofuryl oxalate and pentoxifylline for the treatment of intermittent claudication. Br J Surg. 2012; 
99(12): 1630-1638, doi: 10.1002/bjs.8895, indexed in Pubmed: 23034699.

119. Robertson L, Andras A. Prostanoids for intermittent claudication. Cochrane Database Syst Rev. 2013(4): CD000986, doi: 10.1002/14651858.CD000986.pub3, indexed in Pubmed: 23633305.

120. Coccheri S, Scondotto G, Agnelli G, et al. Arterial Arm of the Suavis (Sulodexide Arterial Venous Italian Study) group. Sulodexide in the treatment of intermittent claudication. Results of a randomized, double-blind, multicentre, placebo-controlled study. Eur Heart J. 2002; 23(I3): 1057-1065, indexed in Pubmed: 12093059.

121. Nicolaï SPA, Kruidenier LM, Bendermacher BLW, et al. Ginkgo biloba for intermittent claudication. Cochrane Database Syst Rev. 2009; 39(2): CD006888-158, doi: 10.1002/1465I858. CD006888.pub2, indexed in Pubmed: 19370657.

122. Salhiyyah K, Senanayake E, Abdel-Hadi M, et al. Pentoxifylline for intermittent claudication. Cochrane Database Syst Rev. 2012; I: CD005262, doi: 10.1002//465 I858.CD005262.pub2, indexed in Pubmed: 2225896I.

123. Thompson PD, Zimet R, Forbes WP, et al. Meta-analysis of results from eight randomized, placebo-controlled trials on the effect of cilostazol on patients with intermittent claudication. Am J Cardiol. 2002; 90(12): 1314-1319, indexed in Pubmed: 12480040.

124. Regensteiner JG, Ware JE, McCarthy WJ, et al. Effect of cilostazol on treadmill walking, community-based walking ability, and health-related quality of life in patients with intermittent claudication due to peripheral arterial disease: meta-analysis of six randomized controlled trials. J Am Geriatr Soc. 2002; 50(12): 1939-1946, indexed in Pubmed: 12473004.

I25. lida O, Yokoi H, Soga Y, et al. STOP-IC investigators. Cilostazol reduces angiographic restenosis after endovascular therapy for femoropopliteal lesions in the Sufficient Treatment of Peripheral Intervention by Cilostazol study. Circulation. 2013; 127(23): 2307-23 15, doi: 10. I 161/CIRCULATIONAHA. I |2.0007| I, indexed in Pubmed: 2365286I.

126. Cosmi B, Conti E, Coccheri S, et al. Anticoagulants (heparin, low molecular weight heparin and oral anticoagulants) for intermittent claudication. Cochrane Database Syst Rev. 200 I(3): CD001999, doi: 10.1002/1465/858.CD001999, indexed in Pubmed: II 687006.

127. Westendorp IC, in't Veld BA, Grobbee DE, et al. Hormone replacement therapy and peripheral arterial disease: the Rotterdam study. Arch Intern Med. 2000; 160(16): 2498-2502, indexed in Pubmed: 10979062.

128. Price J, Leng GC, Price JF, et al. Steroid sex hormones for lower limb atherosclerosis. Cochrane Database Syst Rev. 2000; 10(2): CD000 I88, doi: 10.1002/I465 I858.CD000 I88, indexed in Pubmed: 10796504.

129. Jepson RG, Kleijnen J, Leng GC, et al. Garlic for peripheral arterial occlusive disease. Cochrane Database Syst Rev. 2000(2): CD000095, doi: 10.1002/1465/858.CD000095, indexed in Pubmed: 10796487.
130. Kleijnen J, Mackerras D. Vitamin E for intermittent claudication. Cochrane Database Syst Rev. 2000(2): CD000987, doi: 10.1002/1465 1858.CD000987, indexed in Pubmed: 1079657I.

13I. van Rij AM, Solomon C, Packer SG, et al. Chelation therapy for intermittent claudication. A double-blind, randomized, controlled trial. Circulation. 1994; 90(3): 1194-1199, indexed in Pubmed: 8087928.

132. Ernst E. Chelation therapy for peripheral arterial occlusive disease: a systematic review. Circulation. 1997; 96(3): 10311033, indexed in Pubmed: 9264515.

133. Bedenis R, Stewart M, Cleanthis M, et al. Cilostazol for intermittent claudication. Cochrane Database Syst Rev. 2014(I0): CD003748, doi: 10.1002/1465I858.CD003748.pub4, indexed in Pubmed: 25358850.

134. de Backer TLM, Vander Stichele R, Lehert P, et al. Naftidrofuryl for intermittent claudication. Cochrane Database Syst Rev. 2012(12): CD001368.

135. Murphy TP, Cutlip DE, Regensteiner JG, et al. CLEVER Study Investigators, CLEVER Investigators, CLEVER Steering Committee. The Claudication: Exercise Vs. Endoluminal Revascularization (CLEVER) study: rationale and methods. J Vasc Surg. 2008; 47(6): 1356-1363, doi: 10.1016/j.jvs.2007.12.048, indexed in Pubmed: 18440181.

136. Hood SC, Moher D, Barber GG. Management of intermittent claudication with pentoxifylline: meta-analysis of randomized controlled trials. CMAJ. 1996; 155(8): 1053-1059, indexed in Pubmed: 8873633.

137. Salhiyyah K, Senanayake E, Abdel-Hadi M, et al. Pentoxifylline for intermittent claudication. Cochrane Database Syst Rev. 2012; I: CD005262, doi: 10.1002/1465 I858.CD005262.pub2, indexed in Pubmed: 2225896I.

138. Wong PF, Chong LY, Mikhailidis DP, et al. Antiplatelet agents for intermittent claudication. Cochrane Database Syst Rev. 20II(II): CD00I272, doi: I0.1002/I465I858.CD00I 272. pub2, indexed in Pubmed: 22071801.

139. Libretti A, Catalano M. Treatment of claudication with dipyridamole and aspirin. Int J Clin Pharmacol Res. 1986; 6(I): 59-60, indexed in Pubmed: 3514494.

140. Hiatt WR, Regensteiner JG, Creager MA, et al. Propionyl-L-carnitine improves exercise performance and functional status in patients with claudication. Am J Med. 2001; 1 10(8): 616-622, indexed in Pubmed: 11382369.

14I. Hiatt WR, Creager MA, Amato A, et al. Effect of propionyl-L-carnitine on a background of monitored exercise in patients with claudication secondary to peripheral artery disease. J Cardiopulm Rehabil Prev. 201I; 31(2): 125-132, doi: 10.1097/ HCR.0b0I 3e3 I8IfIfd65, indexed in Pubmed: 20861750.

142. Brevetti G, Perna S, Sabbá C, et al. Propionyl-L-carnitine in intermittent claudication: double-blind, placebo-controlled, dose titration, multicenter study. J Am Coll Cardiol. 1995; 26(6): 1411-1416, doi: 10.1016/0735-1097(95)00344-4, indexed in Pubmed: 7594063.

143. Brass EP, Koster D, Hiatt WR, et al. A systematic review and meta-analysis of propionyl-L-carnitine effects on exercise performance 
in patients with claudication. Vasc Med. 2013; 18(I): 3-12, doi:

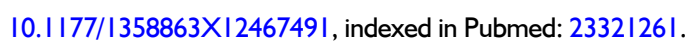

144. Delaney CL, Spark JI, Thomas J, et al. A systematic review to evaluate the effectiveness of carnitine supplementation in improving walking performance among individuals with intermittent claudication. Atherosclerosis. 2013; 229(I): 1-9, doi: 10.1016/j. atherosclerosis.2013.03.004, indexed in Pubmed: 23557982.

145. Böger RH, Bode-Böger SM, Thiele W, et al. Restoring vascular nitric oxide formation by $L$-arginine improves the symptoms of intermittent claudication in patients with peripheral arterial occlusive disease. J Am Coll Cardiol. 1998; 32(5): 1336-1344, indexed in Pubmed: 9809945.

146. Wilson AM, Harada R, Nair N, et al. L-arginine supplementation in peripheral arterial disease: no benefit and possible harm. Circulation. 2007; 116(2): 188-195, doi: 10.1161/CIRCULATIONAHA. 106.683656, indexed in Pubmed: 17592080.

147. Diehm C, Balzer K, Bisler H, et al. Efficacy of a new prostaglandin EI regimen in outpatients with severe intermittent claudication: results of a multicenter placebo-controlled double-blind trial. J Vasc Surg. 1997; 25(3): 537-544, indexed in Pubmed: 9081136.
148. Lièvre M, Morand S, Besse B, et al. Oral Beraprost sodium, a prostaglandin I(2) analogue, for intermittent claudication: a double-blind, randomized, multicenter controlled trial. Beraprost et Claudication Intermittente (BERCl) Research Group. Circulation. 2000; 102(4): 426-431, indexed in Pubmed: 10908215.

149. Mohler E, Hiatt W, Olin J, et al. Treatment of intermittent claudication with beraprost sodium, an orally active prostaglandin I2analogue. Journal of the American College of Cardiology. 2003; 4I(10): 1679-1686, doi: 10.1016/s0735-1097(03)00299-7.

150. Nicolaï SPA, Kruidenier LM, Bendermacher BLW, et al. Ginkgo biloba for intermittent claudication. Cochrane Database Syst Rev. 2009; 39(2): CD006888-158, doi: 10.1002/1465/858. CD006888.pub2, indexed in Pubmed: 19370657.

15I. Stewart M, Morling JR, Maxwell H, et al. Padma 28 for intermittent claudication. Cochrane Database Syst Rev. 2013; 3(7): CD00737I, doi: 10.1002/1465 I858.CD00737I.pub2, indexed in Pubmed: 23861015.

152. Bonaca MP, Creager MA. Pharmacological treatment and current management of peripheral artery disease. Circ Res. 2015 1 16(9): 1579-1598, doi: 10.1 16I/CIRCRESAHA. I 14.303505, indexed in Pubmed: 25908730. 